Archimer, archive institutionnelle de l'Ifremer

\title{
Two- or three-layered box-models versus fine 3D models for coastal ecological modelling? A comparative study in the English Channel (Western Europe)
}

\author{
Alain Ménesguen ${ }^{\mathrm{a},{ }^{*}}$, Philippe Cugier ${ }^{\mathrm{a}}$, Sophie Loyer ${ }^{\mathrm{b}}$, Alice Vanhoutte-Brunier ${ }^{\mathrm{a}}$, Thierry Hoch $^{\mathrm{c}}$, \\ Jean-François Guillaud ${ }^{\mathrm{a}}$ and Francis Gohin ${ }^{\mathrm{a}}$
}

\author{
aIFREMER, Ecosystem Dynamics Department, BP 70, 29280, Plouzané, France \\ ${ }^{\mathrm{b}}$ ATLANTIDE, Technopôle Brest Iroise, Site du Vernis, CS 23866, 29238 Brest Cedex 3, France \\ 'UMR ENVN-INRA Gestion de la santé animale, BP 40706, 44307 Nantes Cedex 3, France
}

\author{
*: Corresponding author : Alain Ménesguen, Département Dynamiques de l'Environnement Côtier, Laboratoire \\ Ecologie benthique IFREMER/Centre de Brest 29280 Plouzané (France) \\ tel: 33298224334 \\ fax: 33298224548 \\ e-mail: amenesg@ifremer.fr
}

\begin{abstract}
The general trend in ecosystem modelling is to improve the spatial resolution by shifting from rough box-models to fine 3D models. Despite the continuous speeding-up of computing, 3D models involving numerous state variables may remain intractable, especially for parameter calibration, when processes with long half-life periods (i.e, from years to decades) are introduced, such as the behaviour of organic matter in sediment and population dynamics of benthic species. In these cases, a first approach can be provided by fast-running box-models, if they take into account the most crucial hydrodynamic properties of the system. In a macrotidal shelf sea such as the English Channel, the long-term horizontal transport can be summarized by the tidal residual circulation, and the vertical stratification can be sketched by a two- or three-layered integral model.
\end{abstract}

This paper compares the results obtained in the English Channel area by the same biogeochemical equations of pelagic primary production, coupled to 1) a two-layered box-model 2) a three-layered box-model (i.e., with an intermediate cline layer between surface and bottom ones) and 3) a finegridded 3D model. Comparison is focused firstly on thermal stratification and summer dinoflagellate blooms in the north-western Channel and secondly on the haline stratification and the sequence of blooms obtained in the eutrophicated Seine river plume. Comparison shows that box-models act as low-pass filters which reproduce correctly the weekly mean time-course, but greatly reduce the variance locally observed in a tide-oscillating plume region. As far as global characteristics are concerned, such as the annual primary production, or the percentage of variation in annual production after reducing the nutrient loadings, the box and 3D models gave very similar results. This conclusion reinforces the usefulness of using box-models as a first approach in long-term processes, for which a long transient phase is expected before reaching the annual periodic solution.

Keywords: Layered box-model; 3D model; Diatom/dinoflagellate succession; Stratification; English Channel 


\section{Introduction}

Several coastal areas in the world have been first studied thanks to boxmodels, and recently revisited with 3D tools: in Europe, the North Sea/English Channel is the best documented of such areas, mainly thanks to the ERSEM project which produced a rigid two-layer model (Baretta et al., 1995) followed by a 3D model (Moll, 2000); Moll and Radach (2003) has given a detailed comparison of the 3D models developed in several countries for this coastal sea. Some lagoons also have been studied with both kinds of models: the Wadden Sea (Veldhuis et al., 1988; Brinkman, 1993; Engelen et al., 2003), the Venice lagoon (Solidoro et al., 1997; Bendoricchio, 2000; Umgiesser et al., 2003) or the French Thau lagoon (Chapelle et al., 2000; Plus et al., 2003). However, few of them have been modelled by the same scientists using similar ecological equations coupled either to a hydraulic box-model or to a fine grid 3D hydrodynamical model. The increase of computer power as well as the fact that the modelling approach is more popular among physical oceanographers than in the biological oceanographers community have recently reinforced the idea that a very realistic 3D hydrodynamical model with fine spatial resolution is an absolutely necessary stage in the development of a complex ecosystem model, especially for operational purposes. Is this always true, or should we utilise different kinds of modelling tools depending on the questions of interest? Some of these obviously deal with long term and/or long range characteristics of the ecosystem dynamics, which can perhaps be appraised thanks to roughly spatiallyresolved models. Some questions (climatic change, benthic biodiversity...) focus on the decadal long-term responses, which require the simulation of very long periods, and make calibration of refined 3D models quasi unfeasible with common computers at this moment: is there still a place for box-models in exploring such questions?

The purpose of this paper is to start from already published two-layered boxmodel and 3D fine-gridded model, to introduce a new three-layered box-model and to compare them on some selected features considered as characteristic of the pelagic ecosystem in the English Channel. The two-layered box-model has been previously fully described for the whole Channel in Ménesguen and Hoch (1997) and Hoch and Ménesguen (1997), and applied again to the restricted area of the Bay of Seine by Guillaud and Ménesguen (1998) and Guillaud et al. (2000). The SiAM3D model has been fully described and applied to the Bay of Seine by Cugier and Le Hir (2002) and Cugier et al. (2005). The MARS3D hydrodynamic model has been described when applied to the French Atlantic shelf by Lazure and Jegou (1998) and coupled to an ecological model on the same area by Loyer (2001); its application to the whole Channel presented here provides a background model to a more specific ongoing project on Phaeocystis bloom modelling. 


\section{Material and methods}

\subsection{The layered box-models}

Ménesguen and Hoch (1997) have described how modelling the effects of physical vertical structure on ecology can be achieved thanks to integral, two-layer models such as Niiler and Kraus's (1977). The wind stress at the sea surface creates a downward turbulent flux of kinetic energy, which tends to mix over a "surface layer" the solar heat and freshwater received through the surface; such an increase of surface layer thickness can be considered as an entrainment of bottom water into the surface layer, with a vertical entrainment velocity web. Simultaneously, the shear stress on the bottom creates an upward turbulent flux of kinetic energy, which tends to mix over a "bottom layer" the bottom water properties. This can be considered as an entrainment of surface water into the bottom layer, with a vertical entrainment velocity wes. Consequently, exchanges between the surface and the bottom layers are managed as opposite advective flows, without any additional diffusion term. Then, following the original approach by Niiler and Kraus (1977), the resulting vertical structure is made of two homogeneous layers ("surface" layer and "bottom" layer), each of them characterised by 3 state variables: mean temperature, mean salinity and thickness of the layer (Fig.1a). Yang (1993) has proposed an improved version of this integral model by inserting a third layer, the pycnocline, between the surface and bottom mixed layers (Fig. 1b). The computation of the varying thickness of this pycnocline is based on two assumptions : temperature and salinity vary linearly with depth in this pycnocline, and turbulent kinetic energy coming from the surface or from the bottom passes through the cline with a decay depending exponentially on the thickness of the pycnocline. Then, exchanges between two superposed layers are still of a pure advective nature (without diffusion), but with an entrainment velocity lower at the distal interface than at the proximal one when looking from the birth place of turbulence. This three-layered model has been implemented in the ELISE software (Ménesguen, 1991), which offers now a simple switch between two- or three layer box-models.

The horizontal transport in linear box-models is handled by an "upwards centered" integration scheme, which is known to be highly diffusive, as far as the time step is lower than the mean residence time in boxes. Then, using tidal instantaneous flow fields between boxes, derived from 2D fine grid hydrodynamical models, is inappropriate. The tide-filtered flow field (the so-called residual tidal flow field) seems more convenient, because it furnishes the slow drift (here from the western approaches of the Channel towards the North Sea). When used on a fine horizontal grid, this advective residual transport has proved to be able to simulate accurately the long-term drift and dispersion of radio-nuclides in the Channel and the North Sea (Bailly du Bois and Dumas, 2005). For this purpose, these authors added an explicit turbulent diffusive term based on the empirical formula $\mathrm{K}=\beta \cdot \mathrm{H} \cdot\|\overrightarrow{\mathrm{u}}\|$, first established for instantaneous flows, but used here with a the mean velocity module over a tidal period instead of the instantaneous velocity module. When used in a boxmodel context, the "upwards centered" integration of this residual advective flow field introduces a numerical diffusion, which mimics part of the real dispersion induced by the oscillating tidal currents. This part can be completed by added explicit diffusion between boxes, as previously explained. Here, fluxes between the boxes are calculated for a medium tidal amplitude from a grid of residual currents having a 
mesh of 1 n.m x 1 n.m (Salomon and Breton, 1991) and proportionally modulated by the daily varying tidal coefficient provided by the French Navy Hydrographic Service (see Ménesguen and Hoch, 1997). Figures 3a and 4a give the box systems used for the whole Channel and the Bay of Seine respectively.

\subsection{The 3D fine-gridded models}

Two different 3D codes (MARS3D and SiAM3D) have been developed by IFREMER for coastal hydrodynamics. Both models solve the primitive equations with free surface, by applying the Boussinesq approximation, hydrostatic equilibrium and incompressibility and using a mode splitting technique. The turbulence closure is provided by one KTE equation using the mixing length concept. Equations are discretised in finite differences on a staggered " $C$ " grid as defined by Arakawa and Lamb (1977).

The whole Channel has been treated here thanks to the MARS3D code (Lazure and Jegou, 1998). It uses regular orthogonal grids with square meshes, aligned with geographic axes, on the horizontal plane (Fig. 2a) and a $\sigma$ discretisation on the vertical axis, which sets the thickness of the layers at values proportional to the local water depth (Fig. 2b). The turbulence closure is provided by a KTE equation using the mixing length concept. The numerical implementation uses a TVD scheme (Harten, 1983) for dissolved/particulate variable transport in combination with a second order Quick scheme (Leonard, 1979) for momentum advection. Figure 3b gives the grid used for the whole Channel.

The Bay of Seine area has been modelled thanks to SiAM3D (Cugier and Le Hir, 2002), because of the need of some local refinement in the Seine plume area. This code can use irregular rectangular grids, with any slant from geographic axes, on the horizontal plane (Fig. 2c) and a z discretisation on the vertical axis, which presets the thickness of the layers at fixed values referred to the hydrographic zero level (Fig. 2d). According to Prandtl's theory (Prandtl, 1925), the turbulence viscosity is related to the local mean velocity gradient and a mixing length. The density induced turbulence damping is parameterized by using a local Richardson number. The numerical implementation uses a Bott's scheme (1989) for dissolved/particulate variable transport. Figure $4 \mathrm{~b}$ gives the grid used for the Bay of Seine.

\subsection{The biogeochemical model}

The same equations have been coupled to the layered box-models and to the 3D fine gridded models. They have been previously described in the Bay of Seine context (Cugier et al., 2005) and Fig. 5 illustrates the conceptual diagram of this simple NPZD model coupling the nitrogen, phosphorus and silicon cycles in water and sediment. Equations can be found in Guillaud et al. (2000) and Cugier et al. (2005). As few parameters have been recalibrated to ensure a better overall fitting to data when the model is applied simultaneously to the whole Channel and to the more restricted area of the Bay of Seine, the new set of parameter values is given in Table 1.

\subsection{The data and procedures used for calibration and validation}

Measurements obtained classically from samples are rather scarce in time, and moreover in space; regular monitoring stations are mostly located very near to the 
coast, and wide open sea areas are never sampled, especially if they don't contain ferry lines equipped with automatic samplers. In order to have a look on the seasonal time course of some basic oceanographic variables ( $T, S$, nutrients, chlorophyll), ancient data collected at two stations have been used as representative of the two different stratified areas in the Channel : for the north-western thermally stratified area, the E1 station followed by the Plymouth Marine Laboratory $\left(50^{\circ} 02^{\prime} \mathrm{N}, 4^{\circ} 22^{\prime} \mathrm{W}\right.$, located on Fig.7a); for the Seine plume area in the eastern Channel, the RNO2 station followed by the French RNO monitoring network and the "Grande Rade" Marel buoy (see location on Fig.4a). For vertical profiles, some data collected by CEFAS during the summer 2003 have been used. In order to be as comparable as possible to these field measurements, all the models have been run with forcing variables (meteorological variables, river flow rates and concentrations) measured on the same year, after a one year spin-up necessary to forget the winter homogeneous initial conditions.

For global validation of the simulated surface layer temperature, some of the best satellite instantaneous views provided by the AVHRR sensors have been used. Because of the transitory strong heating of the few upper centimetres during a sunny day without strong wind ("skin effect"), AVHRR views made at the end of the night, when wind stress has performed some mixing of the heated superficial thin layer, have been preferred to afternoon pictures, as more compatible with the few meter surface layers of the models.

For global validation of chlorophyll, some instantaneous snapshots provided by the SeaWiFS sensor can also be used, as processed by the IFREMER algorithm adapted to coastal data (Gohin et al., 2002), refered as OC5 algorithm later in the text. But for irregular variables showing intermittent bursts as chlorophyll, one may be more interested in looking at characteristics respectively related to the low frequency content, the total spectrum energy, and the high frequency content. For instance, simple processing of all the clear images available from 1998 until 2004 can provide some synthetic maps, as the yearly mean, the annual maximum value and the date of its occurrence. For each pixel, in order not to bias the mean and standard deviation in favour of months of clear sky, existing measurements have been gathered into four seasonal means, and the annual value has been computed as the arithmetic mean of these four seasonal values. For the annual peak, a 365 daily mean series was built, with some missing data, and the maximum observed value was considered as the annual peak. These synthetic parameters may provide a qualitative, but more adapted, assessment of the global fitness of the dynamic behaviour of the model than the classical date-to-date comparison of data and simulation. Ideally, the corresponding simulated results should be computed on a long series of real years, but here they have been computed only for the year 2001. 


\section{Results}

3.1 Modelling the Channel as a whole, with regard to the summer stratification in the north-western area

\subsubsection{Surface and bottom temperature}

The seasonal course of the sea surface temperature is of a sinusoidal type, with minimum in February and maximum in August; local amplitude depends mainly on the bathymetry and the input of buffered oceanic waters. When compared to surface and bottom field measurements obtained for instance in 2003 at E1 station location (Fig. 6), the two-layer box-model attenuates the surface-bottom differentiation and gives a summer bottom temperature one degree too high. This drawback is corrected by the three-layer box-model, but both box-models fail to reproduce the very early beginning of stratification. The MARS3D model gives the better simulation, especially for the bottom layer and for the early stratification episode, but gives too high SST during May and June.

Due to a frequent cloudy weather, a complete cover of the whole Channel by the AVHRR sensor is seldom obtained. The excellent image taken on the $03^{\text {rd }}$ July, 2001 (Fig. 7a) clearly shows the stratified north-western area, with temperature ranging from $17^{\circ} \mathrm{C}$ to $18^{\circ} \mathrm{C}$. This stratified area is separated from the colder and vertically mixed central Channel $\left(\sim 15^{\circ} \mathrm{C}\right)$ by a well-known front (Pingree, 1975$)$. The three-layer box-model (Fig. 7b) gives a realistic pattern of SST distribution, but about $1^{\circ} \mathrm{C}$ too cold in the south-western Channel and too warm in the coastal strip of the north-western Channel. The 3D model (Fig. 7c) also gives patterns consistent with satellite SST-measurements, particularly in the western Channel. The simulated temperature along the coast of the eastern Channel however tends to be $1^{\circ} \mathrm{C}$ overestimated.

\subsubsection{Temperature vertical profile in the north-western Channel}

Thanks to a vertical profile made near station E1 by the CEFAS during its summer cruise CORYSTES8 (Fig. 8), the ability of the three kinds of models to simulate the vertical thermal stratification during a particularly hot year can be assessed. All of them succeed in stratifying the water column, but clearly, the twolayered box-model attenuates the difference between surface and bottom temperature. The three-layer model provides a greater SST than the two-layer one, because of the lower thickness of its surface mixed layer, but temperatures in the three layers are half a degree too cold. The 3D model provides clearly the more realistic vertical profile of temperature.

\subsubsection{Horizontal distribution of the chlorophyll}

The map of chlorophyll annual mean derived from satellite images (Fig. 9a) collected during the 1998-2004 period reveals the poorness of the western Channel and the central canal of the eastern Channel $(<0.75 \mu \mathrm{g} / \mathrm{L}$ chl.a), compared to the coastal waters of this last region $(\sim 1.5 \mu \mathrm{g} / \mathrm{L}$ chl.a along the English coast, up to 2.5 $\mu \mathrm{g} / \mathrm{L}$ chl.a along the French coast). The frequent summer occurrence of dinoflagellate blooms in the north-western stratified area explains the patch of chlorophyll (up to 1.5 
$\mu \mathrm{g} / \mathrm{L}$ for the annual mean!) located in the middle of the western entrance of the Channel.

When converted from nitrogen content to chlorophyll content by dividing by a single Chl:N ratio equal to $1.1 \mu \mathrm{g} . \mu \mathrm{mol}^{-1}$, the sum of the diatom and dinoflagellate state variables of the 2- or 3 layered box-models (Fig. 9b) reproduces this mean distribution of phytoplankton biomass, especially well in the eastern Channel. In the western Channel, biomass is overestimated in the boxes around Channel islands and French Cotentin peninsula; dinoflagellate blooms simulated in summer in the northwestern Channel reach a biomass high enough to slightly exceed the level visible on the satellite map, especially along the Cornwall coast. The 3D simulation (Fig. 9c) gives results similar to the box-models, but overestimates the mean chlorophyll level along the whole English coast, because of too high a growth rate of dinoflagellates in the shallow meshes bordering the English coast. This behaviour of the biological submodel was revealed by the fine resolution of the 3D model and not by the larger, and hence deeper, coastal boxes. Globally lowered and, then, more realistic 3D mean annual chlorophyll distribution has been obtained by increasing the Chl:N ratio up to $1.5 \mu \mathrm{g} . \mu \mathrm{mol}^{-1}$ (not shown).

The annual standard deviation of the total chlorophyll concentration appears to be linked quasi-linearly to the annual mean, as well in the satellite data as in the timeseries simulated by the box-models and the 3D model (Fig. 10). But the models here also behave more smoothly than the field data: the slope of the satellite-derived relationship is more pronounced than the model's ones. Surprisingly, the spatially more refined 3D model does not behave differently from the box-models, and does not succeed in simulating the high time variability of chlorophyll appearing in satellite data, perhaps because the formulation of the biological model is inherently not so reactive, perhaps also because phytoplankton can react to transitory surface microstratifications which are not resolved neither by our layered box-models nor by our 3D model with too few and thick layers.

When extreme instead of mean values are considered, the realism of models dramatically drops down. In the satellite-derived data (Fig. 11a), the date of the peak of the annual mean appears to be situated in spring for regions dominated by diatoms all over the year, i.e. all the eastern Channel and the French coastal waters in the western Channel, but to be shifted into summer in the stratified north-western area, where the biomass of dinoflagellate blooms may override the spring diatom bloom. Roughly speaking, the two layer box-model (Fig. 11b) gives an annual maximum 2 months too early in the stratified north-western area, and 20 to 40 days too late in the mixed western Channel. The 3D model gives very late annual maxima everywhere, except in the Channel isles area (Fig.11c): this appears realistic in the western Channel, but completely out of phase in the eastern Channel. Again, and because of the previously mentioned lack of reactivity in simulated chlorophyll, all these models seem to be unreliable as far as a precise phasing of blooms is required, for instance for operational purposes. This seems to be due to the biological terms of equations more than to the hydrodynamic ones.

\footnotetext{
3.1.4 Vertical distribution of diatoms and dinoflagellates in the stratified region
}

The two-layer box-model (Fig. 12a) shows in the surface layer a main diatom bloom reaching $3.5 \mu \mathrm{g} / \mathrm{L} \mathrm{Chl.a} \mathrm{in} \mathrm{April} \mathrm{and} \mathrm{a} \mathrm{secondary} \mathrm{one} \mathrm{in} \mathrm{September,} \mathrm{reaching} 1$ 
$\mu \mathrm{g} / \mathrm{L}$ Chl.a only. This is in good concordance with observations, as well as the diatom scarcity in the surface mixed layer all over the late spring and the summer. The threelayer box-model improves this simulation because it can reproduce the fact that diatoms continue to grow in the thermocline after the spring surface bloom, using until July the nutrients still available in that region. The 3D model (Fig. 12c) gives results very similar to the three-layer box-model, but with a stronger and longer autumn bloom, which seems slightly overestimated.

Since Holligan and Harbour (1977), several studies have shown that dinoflagellates, especially Karenia mikimotoi (previously known as Gyrodinium aureolum) are well adapted to the summer thermocline system, and tend to build high biomasses first in the cline (around $20 \mathrm{~m}$ deep), then extending to the whole surface mixed layer in July. Every year, these blooms can be seen on satellite colour images, with duration, extension and intensity depending on the meteorology of the year. The very hot spring and summer 2003 were particularly favourable to these toxic blooms, which extended progressively from their usual place, the mid western entrance of the Channel, towards the Channel Isles in the south-east part of the western Channel; on the $15^{\text {th }}$ of August 2003, fish kills were recorded near the French coast.

All the models show dinoflagellates growing only during summer (Fig.12b and 12d), peaking in August. Surprisingly, the 3D behaves more like the two-layer box-model (bloom located in the surface layer) than like the three-layer box-model, which is the only one showing a first phase of dinoflagellate proliferation in the thermocline, followed by a second one where blooming extends to the whole surface mixed-layer. This two-step process is a characteristic feature observed in the field by several scientists (Le Corre and L'Helguen, 1993). But with the actual equations and parameter values, the three models produce dinoflagellate biomasses only about one third only of the observed one in the north-western stratified Channel.

3.2 Modelling the Seine plume effects on the local eutrophication and related mitigation strategies

Whereas thermal stratification in tidal seas can only establish in depths around $50 \mathrm{~m}$ or more, and can produce natural high summer biomasses of dinoflagellates, strong haline stratification usually starts from the coast, in very shallow areas, and can persist to some extent towards the high sea in the plumes of big rivers. The Channel receives only one main freshwater inflow in its eastern part, the river Seine. Despite a mean discharge of $450 \mathrm{~m}^{3} / \mathrm{s}$, with a range from $2000 \mathrm{~m}^{3} / \mathrm{s}$ during floods to $100 \mathrm{~m}^{3} / \mathrm{s}$ at lowest water level, the Seine plume exhibits vertical stratification only in a radius of about $30 \mathrm{~km}$ from the mouth of the river: the tidal currents can mix the whole shallow water column beyond this distance. However, the high nitrate (around $400 \mu \mathrm{mol} / \mathrm{L}$ ) and phosphate (around $20 \mu \mathrm{mol} / \mathrm{L}$ ) levels reached in the river Seine are responsible for a recurrent eutrophication of the eastern Bay of Seine, particularly in the stratified area. Videau et al.(1998) have shown that diatoms are globally dominant all over the year, making repeated blooms from the spring to the autumn, but that dinoflagellates may locally proliferate up to a "red tide" level, especially in the very coastal area situated on the west side of the estuary. This area is also known to be the most favourable spot along the whole French coasts for the toxic dinoflagellate Dinophysis sp. (Belin and Raffin, 1998).

3.2.1 Salinity and temperature near the surface and near the bottom in the plume area 
Measurements made during 1978 at the French monitoring station RNO2 (see location on Fig. 4a) have been used for the calibration of the two-layer box-model by Guillaud and Ménesguen (1998). This data set clearly shows a haline stratification during the whole year (Fig. 13a and 13b). In winter and spring, the positive buoyancy brought by large freshwater inputs can even largely override the negative buoyancy caused by the river water colder than the sea water one. In summer, temperature and salinity gradients act in the same way. As the vertical density gradient is strong in the pycnocline, the three-layer model behaves here as a two-layer one, with a cline layer reduced to the imposed lowest thickness, i.e. $0.50 \mathrm{~m}$. The two-layer box-model simulates the seasonal trend of the surface- and bottom salinities (Fig. 13a) but overestimates the thermal stratification inversion during winter and seems to react more slowly than the real ecosystem to warming and cooling episodes. The 3D model gives similar results but with a higher variance in salinity (Fig. 13b), due to its capability to simulate the instantaneous, tidally oscillating velocity fields instead of using a unique pattern of residual flows, as does the box-model. For temperature, the short period fluctuations simulated by the 3D model (Fig. 13d) are much smaller than for salinity, and the 3D results look more like the two-layer box-model ones (Fig. 13c), but with a smaller difference between surface and bottom. This different behaviours of temperature and salinity in the two models are linked to the fact that the thermal budget is mainly vertically controlled and hence, more homogeneous all over the Bay of Seine, whereas the salinity one is mainly horizontally controlled by transport and exhibits strong gradients in an estuary-plume area, which can be more accurately simulated by a fine grid 3D model than by a rough box-model. The lowpass filtering effect of the box-model relative to the 3D model can be quantified by computing the transfer function between two comparable simulated time series, for instance results obtained by the two-layer box-model and the 3D model every 10 minutes at station RNO2 during the year 1978. Figure 14 shows that the box-model attenuates by a factor 4 all the salinity fluctuations having periods lower than 2 weeks in the 3D model, and even more in the surface layer. For temperature on the contrary, the box-model behaves slightly as the 3D model in the surface layer, at all frequencies, and only halves the salinity fluctuations having periods lower than 1 month in the bottom layer.

\subsubsection{Horizontal distribution of the chlorophyll}

The classical pattern of eutrophication in the eastern Bay of Seine, as described by previous studies (Guillaud and Ménesguen, 1998; Cugier et al., 2005), is well illustrated by the SeaWiFS satellite picture taken on July 30, 2001 (Fig. 15a). The maximum chlorophyll concentration in summer is to be found in a circular sector enriched by the tidally oscillating plume of the Seine river, going from Antifer cape in the North to Ouistreham in the south; it is separated from the estuary by a turbid area with low chlorophyll and connected to the high sea by some phytoplankton-rich indentations. The 3D model (Fig.15c) reproduces the phytoplankton maximum in the Antifer-Ouistreham arc, but with too low values, especially in the south. The threelayer box-model (Fig.15b) fails to simulate the unproductive, turbid area in the vicinity of the estuary, and greatly underestimates the bloom in the Seine plume and its westerwards extension along the southern coast. All these models underestimate high chlorophyll content of sudden surface blooms and overestimate the between blooms concentrations. Their tendency, whatever their type, to act as low-pass filters 
is well illustrated by comparison of the total surface chlorophyll simulations with the available series of "Grande Rade" Marel buoy measurements (see location on Fig.4a) made in 2001, with a 6 hours time step (Fig. 16). During the first half of June (days 150 to 168), the buoy series shows two great peaks of chlorophyll (around $20 \mu \mathrm{g} . \mathrm{L}^{-1}$ chl.), separated by very low values (around $2 \mu$ g. $L^{-1}$ chl.). The first peak (day 157) occurs at spring tide, but after 3 sunny days (14h insolation per day at days 153 and 154, 9h at day 155), the second one (day 166) occurs classically at neap tide, and also after 2 moderately sunny days (8h insolation per day at days 164 and 165). In spite of a considerably more realistic simulation of the stratification (12 layers instead of 2 or 3) and the horizontal spreading of the Seine plume (instantaneous tidal and winddriven circulation instead of wind independent stable residual circulation), the 3D model does not produce in that place a chlorophyll simulation better than the boxmodels. The observed two oscillations are reproduced, but with a considerable attenuation (by a factor 10), and with one day lag for the second peak.

\subsubsection{Determining the limiting nutrient}

The two-layer box-model (Guillaud et al., 2000) and the 3D model (Cugier et al., 2005) of the Bay of Seine have already been used separately to assess the succession of phytoplankton growth limitations during the year. Steele's factor used by the models for light effect and Michaelis ones used for N, P, Si limiting effects vary from 0 (growth total inhibition) to 1 (no limitation at all), and can be used for assessing the most limiting factor. Comparison of the limiting factors for diatom growth computed at station RNO2 in 1978 by the two models (Fig. 17) shows again the strong low-pass filtering effect of the box-model using residual circulation, but also that the ranking of the different limiting factors at any moment is the same in both models: light is the first limiting factor during late autumn and winter, nutrients are limiting in spring and summer. Both models reveal that in 1978, phosphorus was never limiting (silicon was the main limiting factor after the spring bloom, nitrogen became the most limiting during summer), whereas in 1995, phosphorus had become the first limiting factor after the spring bloom, and silicon the limiting factor during summer, nitrogen remaining unlimiting all over the year. This was a consequence of a drastic reduction of $\mathrm{P}$ loadings coming from fertilizer industry and urban sewage, contrasting with a continuous increase of $\mathrm{N}$ loadings coming from agricultural nonpoint sources (Ménesguen et al., 1995).

\subsubsection{Assessing the effects of various loading reduction scenarios}

Another classical use of models in eutrophication problems is the simulation of various scenarios of loading reduction. As far as yearly integrated characteristics, such as annual production of phytoplankton in a certain area, are used as assessment criteria, it is not surprising that low-pass filters such as box-models give results comparable to full 3D models. For dinoflagellate annual productions in the Seine plume area (Fig. 18c and 18d), both models give a significant lowering by severe reduction of $\mathrm{P}$ and especially $\mathrm{N}$ loadings. But for peak values, such as annual maximum diatom concentration in the Seine plume area (Fig. 18a and 18b), both models also give similar results: no effect of $\mathrm{N}$ loadings reduction (because diatom blooms are now either P-limited, or Si-limited), and a small effect of P loadings 
reduction, because summer diatom blooms, which can override the spring bloom in some sub-areas of the zone of interest are rather Si-limited.

\section{Discussion}

The compartmental approach (i.e. box-model) is best suited for naturally dispersive and vertically homogeneous systems. It can be extended to stratified systems thanks to the mixed layer integral approach developed by Niiler and Kraus (1977). The system of linear Ordinary Differential Equations obtained for a conservative tracer has the advantage of having a complete analytical solution and known spectral properties. But the compartmental approach requires a meaningful splitting of the domain into boxes, which is not straightforward: results obtained from a previous fine grid 2D hydrodynamical model may help for this stage. Recently, Solidoro et al. (2004) also used a fine 2D hydrodynamical FEM-model to build "a 10box model for the lagoon of Venice, which might be useful to members of the scientific community seeking first-order assessments of interactions between physical, chemical and biological factors in a spatially non-homogeneous frame, without having to deal with the complexity of a real coupled model”.

Conversely, boxes give "built-in" piecewise integrated results, i.e. low-pass filtered results easily understandable by the end-user without any statistical postprocessing of the results, and fully adapted to questions dealing with long-term, longrange trends. One of the most useful properties of the box-models is their short computing time: for the Bay of Seine, the two layer model presented here was 13 times quicker than the 3D, and the three layer one 4 times quicker. Then, the compartmental approach remains recommended for research purposes such as calibrating new biological processes or simulating slow ecological processes over many decades. It gives reliable results about seasonal and yearly trends. Such a conclusion had been previously drawn by Oguz et al. (2001) for 1D vertical modelling of stratified areas, such as the Black Sea, but the computation of their intermediate layer was not based on fluid mechanics assumptions as here: they defined the intermediate layer as extending from the bottom of the surface mixed layer to the bottom of the euphotic layer, that is to say more as an ecological cline than a pure pycnocline.

A large domain of research where box-models are particularly well-suited is the study of benthic community installation, regulation or disruption by invasive species, such as the limpet Crepidula fornicata in the Channel. A first attempt to understand the steady state distribution of the banded carpet shell (Paphia rhomboïdes) using the Channel ecosystem box-model presented here can be found in Savina (2004).

The fine grid 3D approach is best suited for advective systems with sharp horizontal gradients, but even for a simple conservative substance, the corresponding Partial Differential Equations don't have any analytical solution. One of the main advantages of the 3D models is their ability to produce refined spatial structures from a purely regular grid, without any pre-existing knowledge; but optimisation of their computing time requires the design of irregular adaptative grids, and hence, some preexisting geographical information. Using very fine grids provides well resolved results in space and time, taking into account a large band of frequencies. But the counterpart of this refinement is the creation of huge result data bases, requiring synthesis to be tractable. This kind of low-pass post-processing will provide results unattainable to models with coarser resolution only in cases of strong non-linearity of 
the processes involved. Therefore, the high resolution 3D models can be recommended when a significant part of the phenomenon under study is suspected to take place in structures finely resolved in space. The rapidly increasing computing time when resolution is enhanced argues in favour of applications where short term phenomena dominate. Obtaining highly reliable results about weekly and monthly trends is of prime interest in coastal operational oceanography, a domain where 3D models will be of great value. However, as suggested here by the case of inadequate phasing of simulated chlorophyll maximum, some substantial improvement in simulating biological state variables will arise from a better formulation of physiological processes, not from an endless refinement of spatial resolution. For testing new physiological sub-models, box-models are still the quickest tools, and may be used before plugging these new sub-models in big 3D models. 


\section{Acknowledgements}

We thank J.C. Salomon and M. Breton (Seamer) for having provided the lagrangian residual flow field of the English Channel used for the horizontal transport in the boxmodels, Dr. Matthew Frost for some data collected by the MECN and MBA at station E1, and Dr. Liam Fernand (CEFAS) for some data collected during the CEFAS cruise CORYSTES8. We thank the NASA for having provided free of charge SeaWiFS radiance data, and MétéoFrance/EUMETSAT for SST/AVHRR data. 


\section{References}

Arakawa A. and Lamb V.R., 1977. Computational Design of the Basic Dynamical Processes of the UCLA General Circulation Model. In: Chang J. (Ed.) General Circulation Models of the Atmosphere, Methods in Computational Physics: Advances in Research and Applications, Academic Press, 173-265.

Bailly du Bois P. and Dumas F., 2005. Fast hydrodynamic model for medium- and long-term dispersion in seawater in the English Channel and southern North Sea, qualitative and quantitative validation by radionuclide tracers. Ocean Modelling, 9(2), 169-210.

Baretta J.W., Ebenhöh W. and Ruardij P., 1995. The European regional Seas Ecosystem Model, a complex marine ecosystem model. Neth. J. Sea Res., 33(3/4): 233-246.

Belin C. and Raffin B., 1998. Les espèces phytoplanctoniques toxiques et nuisibles sur le littoral français de 1984 à 1995, résultats du REPHY (réseau de surveillance du phytoplancton et des phycotoxines). Rapport Ifremer RST.DEL/MP-AO 98-16, 283 p.

Bendoricchio G., 2000. Modelling trophic evolution of the Venice Lagoon. In: Lasserre A. and Marzollo A. (Eds.), The Venice lagoon ecosystem, Man and the biosphere series, UNESCO 25, pp. 441-454.

Bott, A., 1989. A positive definite advection scheme obtained by non-linear renormalization of the advective fluxes. Monthly Weather Review, 117: 1006-1015.

Brinkman, A.G., 1993. Biological processes in the EcoWasp ecosystem model. Institute for Forestry and Nature Reserve/ IBN-DLO Report 93/6, 111 p.

Chapelle A., Ménesguen A., Deslous-Paoli J. M., Souchu P., Mazouni N., Vaquer A. and Millet B., 2000. Modelling nitrogen, primary production and oxygen in a mediterranean lagoon. Impact of oysters farming and inputs from the watershed. Ecological modelling 127 (2-3): 161-181.

Cugier, P. and Le Hir, P., 2002. Development of a 3D hydrodynamical model for coastal ecosystem modelling. Application to the plume of the Seine River. Estuar. Coast. Shelf Sc., 55: 673-695.

Cugier, P., Ménesguen A. and Guillaud, J. F., 2005. Three dimensional (3D) ecological modelling of the Bay of Seine (English Channel, France). Journal of Sea Research, 54: 104-124.

Engelen G., Uljee I. and van de Ven K., 2003. WADBOS: Integrating knowledge to support policy-making in the Dutch Wadden Sea. In: Geertman S., Stillwell J. (Eds.), Planning Support Systems in Practice, Advances in Spatial Science, Springer-Verlag, pp. 513-537.

Gohin F., Druon J.N., and Lampert L., 2002. A five channel chlorophyll algorithm applied to SeaWiFS data processed by SeaDAS in coastal waters. International Journal of Remote Sensing, 23(8):1639-1661. 
Guillaud J.F., Andrieux F. and Ménesguen A., 2000. Biogeochemical modelling in the Bay of Seine (France) : an improvement by introducing phosphorus in nutrient cycles. J. Mar. Systems, 25: 369-386.

Guillaud J.F. and Ménesguen A., 1998. Modélisation sur vingt ans (1976-1995) de la production phytoplanctonique en Baie de Seine (France), Oceanol. Acta, 21(6): 887906.

Harten A., 1983. High resolution schemes for hyperbolic conservation laws. J. Comput. Phys. 49: 357-393.

Hoch T. and Ménesguen A., 1997. Modelling the biogeochemical cycles of elements limiting primary production in the English Channel. II. Sensitivity analyses. Mar. Ecol. Prog. Ser. 146: 189-205.

Holligan P.M. and Harbour D.S., 1977. The vertical distribution and succession of phytoplankton in the western English Channel in 1975 and 1976. J. mar. biol. Ass. U.K., 57: 1075-1093.

Lazure P. and Jégou A.M., 1998. 3D modelling of seasonal evolution of Loire and Gironde plumes on Biscay Bay Continental Shelf. In: "5éme Colloque International d’Océanographie du Golfe de Gascogne". La Rochelle, avril 1996. Oceanol. Acta, 21(2): 165-177.

Le Corre P. and L'Helguen S., 1993. Nitrogen source for uptake by Gyrodinium cf. aureolum in a tidal front. Limnol. Oceanogr., 38 (2): 446-451.

Leonard B.P., 1979. A stable and accurate convective modelling procedure based on quadratic upstream interpolation, Comp. Methods Appl. Mech. Eng., 19: 59-99.

Loyer S., 2001. Modélisation de la production phytoplanctonique dans la zone côtière atlantique enrichie par les apports fluviaux. Ph.D Thesis, Paris 6 University, 232 p. tannexes.

Ménesguen A., 1991. "ELISE", an interactive software for modelling complex aquatic ecosystems. in : "Computer Modelling in Ocean Engineering 91", Arcilla et al. (eds), Proc. 2nd. Int. Conf., 30 sept.-4 oct. 1991, Barcelone (Espagne), Balkema, Rotterdam, 87-94.

Ménesguen, A., Guillaud, J. F., Aminot, A. and Hoch, T., 1995. Modelling the eutrophication in a river plume: the Seine river case study (France). Ophelia, 42: 205225.

Ménesguen A. and Hoch T., 1997. Modelling the biogeochemical cycles of elements limiting primary production in the English Channel. I. Role of thermohaline stratification. Mar. Ecol. Prog. Ser. 146: 173-188. 
Moll A., 2000. Assessment of three-dimensional physical-biological ECOHAM1 simulations by quantified validation for the North Sea with ICES and ERSEM data. ICES Journal of Marine Science 57: 1060-1068.

Moll A. and Radach G., 2003. Review of three-dimensional ecological modelling related to the North Sea shelf system - Part 1: Models and their results. Progress in Oceanography, 57(2): 175-217.

Niiler P.P. and Kraus E.B., 1977. One-dimensional models of the upper ocean. In, Modelling and prediction of the upper layers of the ocean. In: Kraus E.B. (Ed.). Proceedings of a NATO advanced Study Institute. Pergamon Press, pp. 145-172.

Oguz T., Malanotte-Rizzoli P. and Ducklow H.W., 2001. Simulations of phytoplankton seasonal cycle with multi-level and multi-layer physical-ecosystem models: the Black Sea example, Ecological Modelling, 144: 295-314.

Pingree R.D., 1975. The advance and retreat of the thermocline on the continental shelf. J. mar. boil. Ass. U.K., 55: 965-974.

Plus M., Chapelle A., Ménesguen A., Deslous-Paoli J.-M. and Auby I., 2003. Modelling seasonal dynamics of biomasses and nitrogen contents in a seagrass meadow (Zostera noltii Hornem.): application to the Thau lagoon (French Mediterranean coast). Ecological Modelling, 161(3): 211-236.

Prandtl, L., 1925. Bericht über Untersuchungen zur ausgebildeten Turbulenz. Z. Angew. Math. Mech., 5: 136-139.

Salomon, J.C. and Breton, M., 1991. Courants résiduels de marée dans la Manche. Oceanol. Acta 11: 47- 53.

Savina M., 2004. Modélisation écologique des populations de palourdes roses (Paphia rhomboïdes) et d'amandes de mer (Glycymeris glycymeris) en Manche. PhD thesis, Univ. of Aix-Marseille II, France

Solidoro C., Melaku Canu D., Cucco A. and Umgiesser G., 2004. A partition of the Venice Lagoon based on physical properties and analysis of general circulation. Journal of Marine Systems, 51(1-4): 147-160.

Solidoro C., Pecenik G., Pastres R., Franco D. and Dejak C., 1997. Modelling macroalgae (Ulva rigida) in the Venice lagoon: Model structure identification and first parameters estimation. Ecological Modelling, 94: 191-206.

Umgiesser G., Canu D.M., Solidoro C. and Ambrose R., 2003. A finite element ecological model: a first application to the Venice Lagoon. Environ. Model. Software Environ. Data News, 18(2), 131-145.

Veldhuis M.J.W., Colijn F., Venekamp L.A.H. and Villerius L., 1988. Phytoplankton primary production and biomass in the western Wadden Sea (The Netherlands); a comparison with an ecosystem model. Neth. J. Sea Res. 22(1): 37-49.

Videau, C., Ryckaert, M. and L'Helguen, S., 1998. Phytoplancton en baie de Seine. Influence du panache fluvial sur la production primaire. Oceanologica Acta, 21: 907921.

Yang D., 1993. The three-layer model of the thermohaline structure in the shallow seas. Acta Oceanologica Sinica. 12(3): 323-334. 


\section{Figure captions}

Figure 1. Diagrams of the two-layered (a) and three-layered (b) box-models, with main forcing and state variables involved.

Figure 2. Schematic view of the horizontal and vertical discretisation used by the MARS3D and SiAM3D codes.

Figure 3. Box-model (a) and regular square grid (b) used for the whole Channel.

Figure 4. Box-model (a) and irregular rectangular grid (b) used for the Bay of Seine.

Figure 5. Conceptual diagram of the biogeochemical model.

Figure 6. Annual course of sea surface temperature in the vicinity of E1 station during 2003, measured by Marine Environmental Change Network and Marine biological Association of the UK., simulated by the two-layered box-model, the three-layered box-model and the MARS3D model.

Figure 7. Sea surface temperature in the whole Channel, on July $3^{\text {rd }}$, 2001, measured by AVHRR satellite sensor (a), simulated by the three-layer box-model (b), and the MARS3D model (c).

Figure 8. Measured versus simulated thermal stratification in the north-western Channel in June 2003.

Figure 9. Maps of the annual mean of the total chlorophyll content in the surface water: satellite-derived data (a), two layer box-model result (b), 3D model result (c).

Figure 10. Relationship between annual standard deviation and mean of the total chlorophyll content in the pixels of satellite imagery (rough data and data pooled by boxes of the box-model), in the boxes of the two layer-model and in the meshes of the 3D model.

Figure 11. Geographic distribution of the date (julian days) of annual peak of total phytoplankton biomass: derived from satellite imagery (a), simulated by the two-layer box-model (b) and by the 3D model (c).

Figure 12. Simulated annual time-course of phytoplankton vertical profiles at station E1. Left: diatoms, right: dinoflagellates. Upper row: 2-layer box-model, mid row: 3layer box-model, bottom row: 3D model.

Figure 13. Simulated annual time-course of salinity (upper row) and temperature (lower row) at station RNO2 during the year 1978; left: surface and bottom layers of the two-layer box-model; right: surface and bottom layers of the 3D model; dots: RNO measurements.

Figure 14. Transfer functions from the 3D model towards the two-layer box-model at station RNO2, for surface and bottom salinity (a), and temperature (b). 
Figure 15. Example of eutrophication in the Seine plume. Surface total chlorophyll measured on July 30, 2001 by SeaWiFS satellite sensor and processed by OC5 algorithm (a), and computed by the three-layer box model (b), and the 3D model (c).

Figure 16. Annual time-course of total surface chlorophyll in 2001 at "La Grande Rade" station, measured by Marel buoy and on SeaWiFS images, and simulated by the 2- and 3-layer box-models as well as by the 3D model.

Figure 17. Annual time-course of the limiting effects of light (red), nitrogen (green), phosphorus (black) and silicon (yellow) on the diatom growth in the surface waters at station RNO2 during the years 1978 (upper figures) and 1995 (bottom figures), computed by the two-layer box-model (left column) and 3D model (right column).

Figure 18. Simulated effects of three levels of reduction of the $\mathrm{N}$ or $\mathrm{P}$ loadings from the river Seine, as obtained by the two-layer box-model (left column) and the 3D model (right column). Upper figures: effects on the diatom annual maximum concentration in the plume area, bottom figures: effects on the annual dinoflagellate production in the same area. 


\section{Table}

\begin{tabular}{|c|c|c|c|}
\hline Symbol & Meaning & Unit & Value \\
\hline \multicolumn{4}{|c|}{ Diatoms } \\
\hline$\mu_{\text {maxdiat }}$ & Maximum growth rate at $0^{\circ} \mathrm{C}$ & $\mathrm{d}^{-1}$ & 0.55 \\
\hline $\mathrm{I}_{\text {optdiat }}$ & Optimal light intensity & $\mathrm{W} \mathrm{m} \mathrm{m}^{-2}$ & 70 \\
\hline $\mathrm{K}_{\text {Ndiat }}$ & Half saturation constant for $\mathrm{N}$ & $\mu \mathrm{mol} \mathrm{dm}{ }^{-3}$ & 2 \\
\hline $\mathrm{K}_{\text {Sidiat }}$ & Half saturation constant for Si & $\mu \mathrm{mol} \mathrm{dm} \mathrm{d}^{-3}$ & 1 \\
\hline$K_{\text {Pdiat }}$ & Half saturation constant for $\mathrm{P}$ & $\mu \mathrm{mol} \mathrm{dm} \mathrm{dm}^{-3}$ & 0.15 \\
\hline $\mathrm{V}_{\text {sdiatmin }}$ & Minimal sedimentation velocity & $\mathrm{m} \mathrm{d}^{-1}$ & 0.5 \\
\hline $\mathrm{V}_{\text {sdiatmax }}$ & Maximal sedimentation velocity & $\mathrm{m} \mathrm{d}^{-1}$ & 1.2 \\
\hline $\mathrm{m}_{\text {diat }}$ & Mortality rate at $0^{\circ} \mathrm{C}$ & $\mathrm{d}^{-1}$ & 0.035 \\
\hline $\mathrm{r}_{\mathrm{Si} / \mathrm{N}}$ & $\mathrm{Si} / \mathrm{N}$ ratio & $\mathrm{mol} \mathrm{mol}^{-1}$ & 0.4 \\
\hline $\mathrm{r}_{\mathrm{P} / \mathrm{N}}$ & $\mathrm{P} / \mathrm{N}$ ratio & $\mathrm{mol} \mathrm{mol}^{-1}$ & 0.0625 \\
\hline $\mathrm{r}_{\mathrm{N} / \text { chloro }}$ & $\mathrm{N} /$ chlorophyll $a$ ratio & $\mathrm{mol} \mathrm{g}^{-1}$ & 1.1 \\
\hline \multicolumn{4}{|c|}{ Flagellates } \\
\hline$\mu_{\operatorname{maxflag}}$ & Maximum growth rate at $0^{\circ} \mathrm{C}$ & $\mathrm{d}^{-1}$ & 0.35 \\
\hline $\mathrm{I}_{\text {optflag }}$ & Optimal light intensity & $\mathrm{W} \mathrm{m} \mathrm{m}^{-2}$ & 120 \\
\hline $\mathrm{K}_{\text {Nflag }}$ & Half saturation constant for $\mathrm{N}$ & $\mu \mathrm{mol} \mathrm{dm} \mathrm{d}^{-3}$ & 0.5 \\
\hline $\mathrm{K}_{\text {Pflag }}$ & Half saturation constant for $\mathrm{P}$ & $\mu \mathrm{mol} \mathrm{dm} \mathrm{dm}^{-3}$ & 0.10 \\
\hline $\mathrm{m}_{\text {flag }}$ & Mortality rate at $0^{\circ} \mathrm{C}$ & $\mathrm{d}^{-1}$ & 0.027 \\
\hline \multicolumn{4}{|c|}{ Zooplankton } \\
\hline$\mu_{\operatorname{maxzoo}}$ & Maximum growth rate at $0^{\circ} \mathrm{C}$ & $\mathrm{d}^{-1}$ & 0.3 \\
\hline Ass & Assimilation & dimensionless & 0.6 \\
\hline$\gamma_{z o o}$ & Slope of Ivlev function & $\mathrm{dm}^{3} \mu \mathrm{g}^{-1}$ & 0.24 \\
\hline $\mathrm{Pr}_{\text {th }}$ & Chlorophyll predation threshold & $\mu \mathrm{g} \mathrm{dm}{ }^{-3}$ & 0.75 \\
\hline $\operatorname{excr}_{\mathrm{zoo}}$ & Excretion & $\mathrm{d}^{-1}$ & 0.01 \\
\hline$m_{\text {minzoo }}$ & Minimum mortality rate at $0^{\circ} \mathrm{C}$ & $\mathrm{d}^{-1}$ & 0.04 \\
\hline$m_{\mathrm{fzoo}}$ & Biomass dependent mortality rate at $0^{\circ} \mathrm{C}$ & $d^{-1} \mu g^{-1} d^{3}$ & 0.0005 \\
\hline $\mathrm{r}_{\mathrm{N} / \mathrm{dwzoo}}$ & $\mathrm{N} /$ dry weight ratio & $\mu \mathrm{mol} \mu \mathrm{g}^{-1}$ & 0.0055 \\
\hline \multicolumn{4}{|c|}{ Particulate adsorbed phosphorus and detrital organic matter } \\
\hline $\mathrm{k}_{\text {desorp }}$ & Phosphorus desorption rate & $\mathrm{d}^{-1}$ & 2.4 \\
\hline $\mathrm{k}_{\mathrm{adsorp}}$ & Phosphorus adsorption rate & $\mathrm{d}^{-1} \mathrm{dm}^{3} \mu \mathrm{mol}^{-1}$ & 0.12 \\
\hline $\mathrm{Q}_{0 \operatorname{maxSM}}$ & $\begin{array}{l}\text { Max. P adsorption capacity (suspended } \\
\text { matter) }\end{array}$ & $\mu \mathrm{mol} \mathrm{g}{ }^{-1}$ & 7 \\
\hline $\mathrm{k}_{\operatorname{minN}}$ & $\mathrm{N}$ mineralization rate at $0^{\circ} \mathrm{C}$ & $d^{-1}$ & 0.05 \\
\hline $\mathrm{k}_{\text {nitrif }}$ & Nitrification rate at $0^{\circ} \mathrm{C}$ & $d^{-1}$ & 0.2 \\
\hline $\mathrm{k}_{\min \mathrm{P}}$ & $\mathrm{P}$ mineralization rate at $0^{\circ} \mathrm{C}$ & $d^{-1}$ & 0.1 \\
\hline $\mathrm{k}_{\text {diss }}$ & Si dissolution rate at $0^{\circ} \mathrm{C}$ & $d^{-1}$ & 0.07 \\
\hline
\end{tabular}

Table 1 

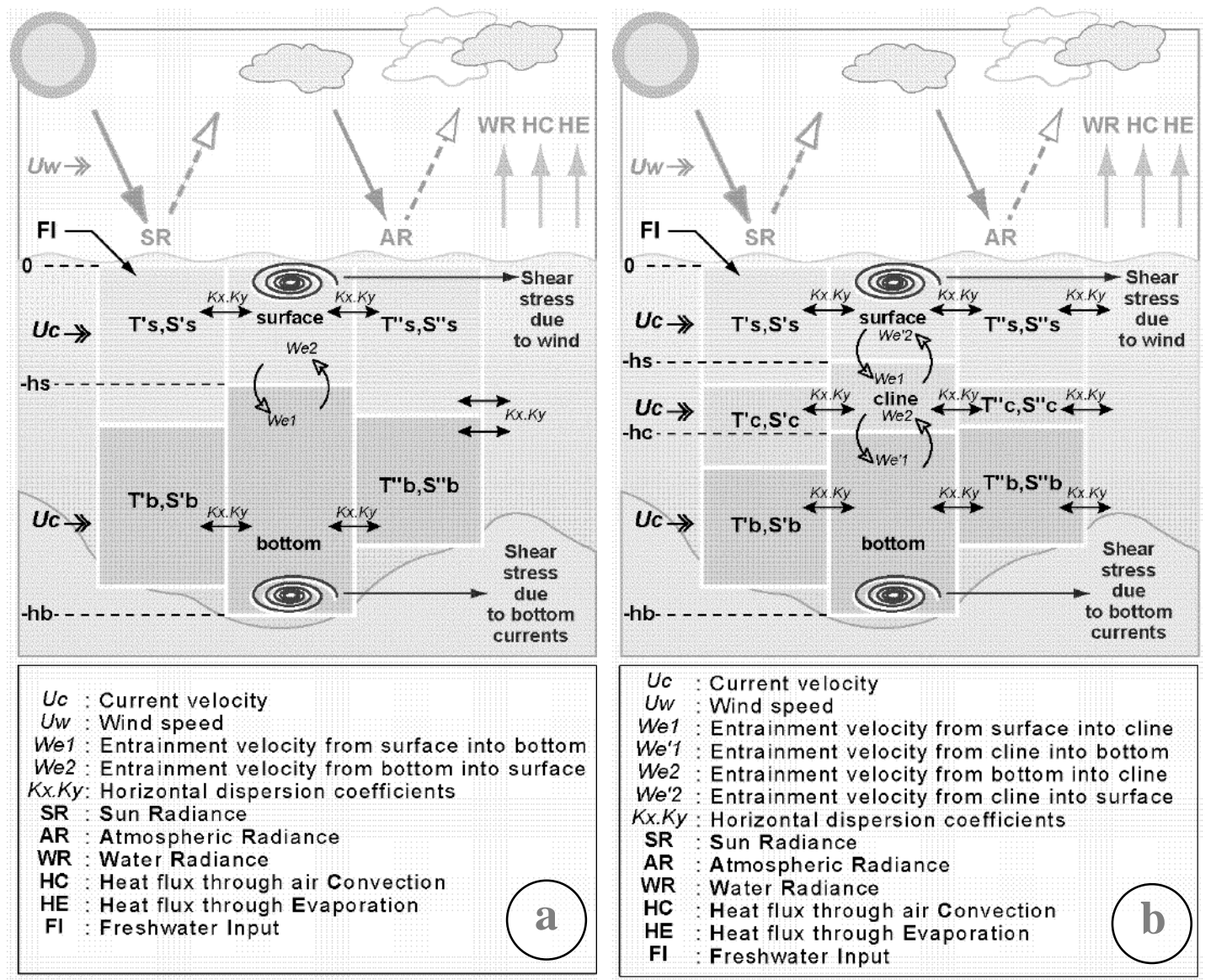

Fig.1 


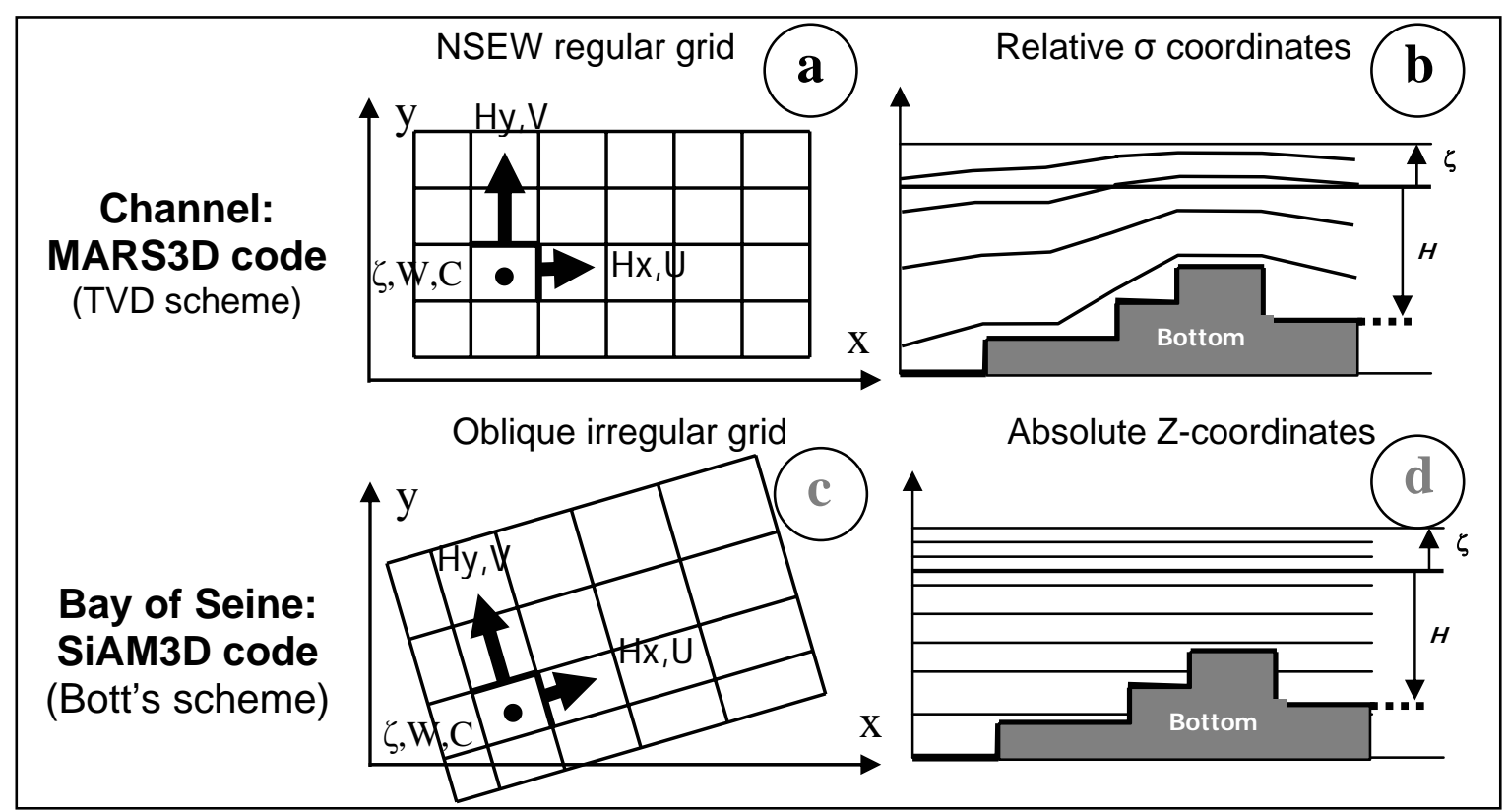

Fig.2 

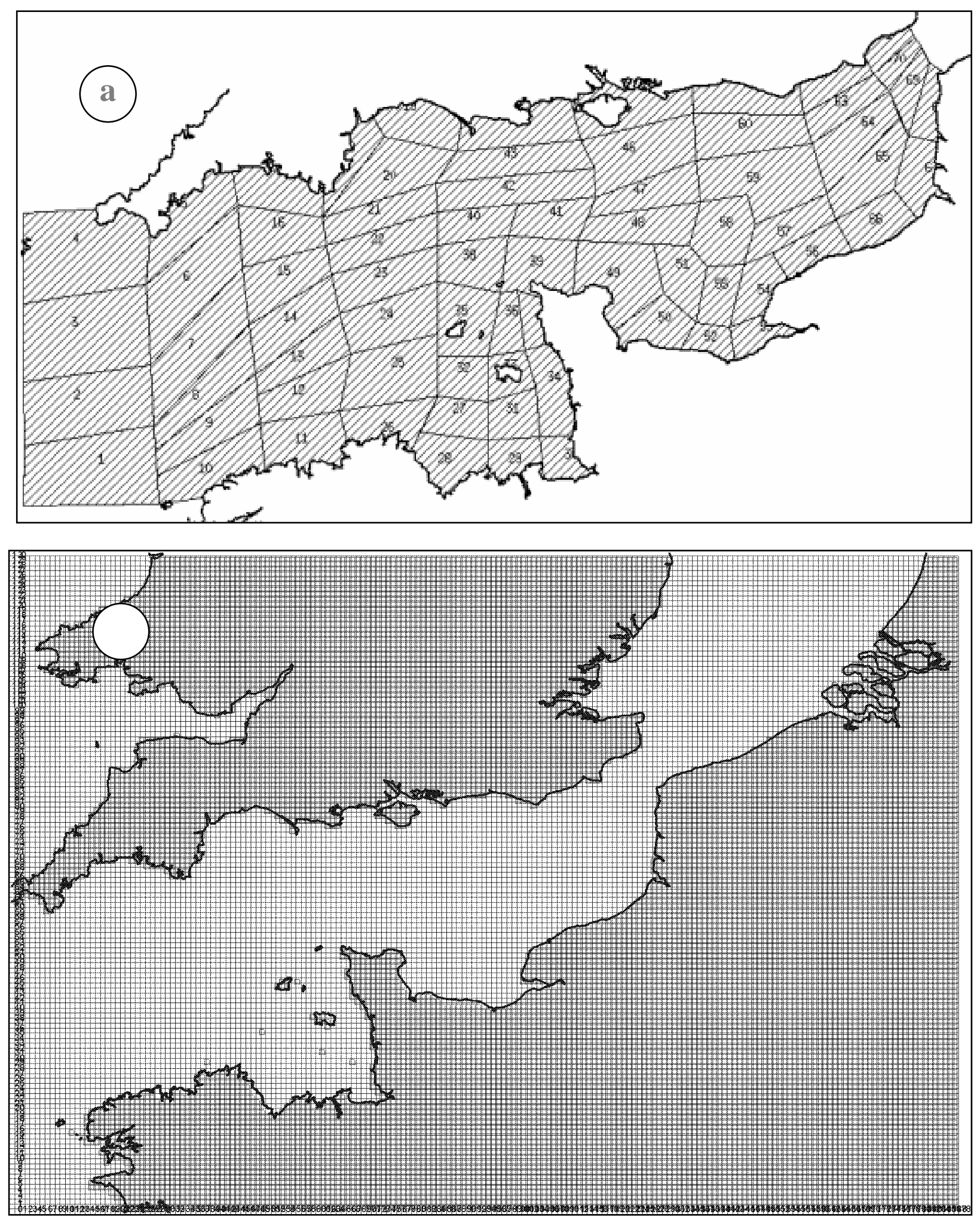

Fig.3 

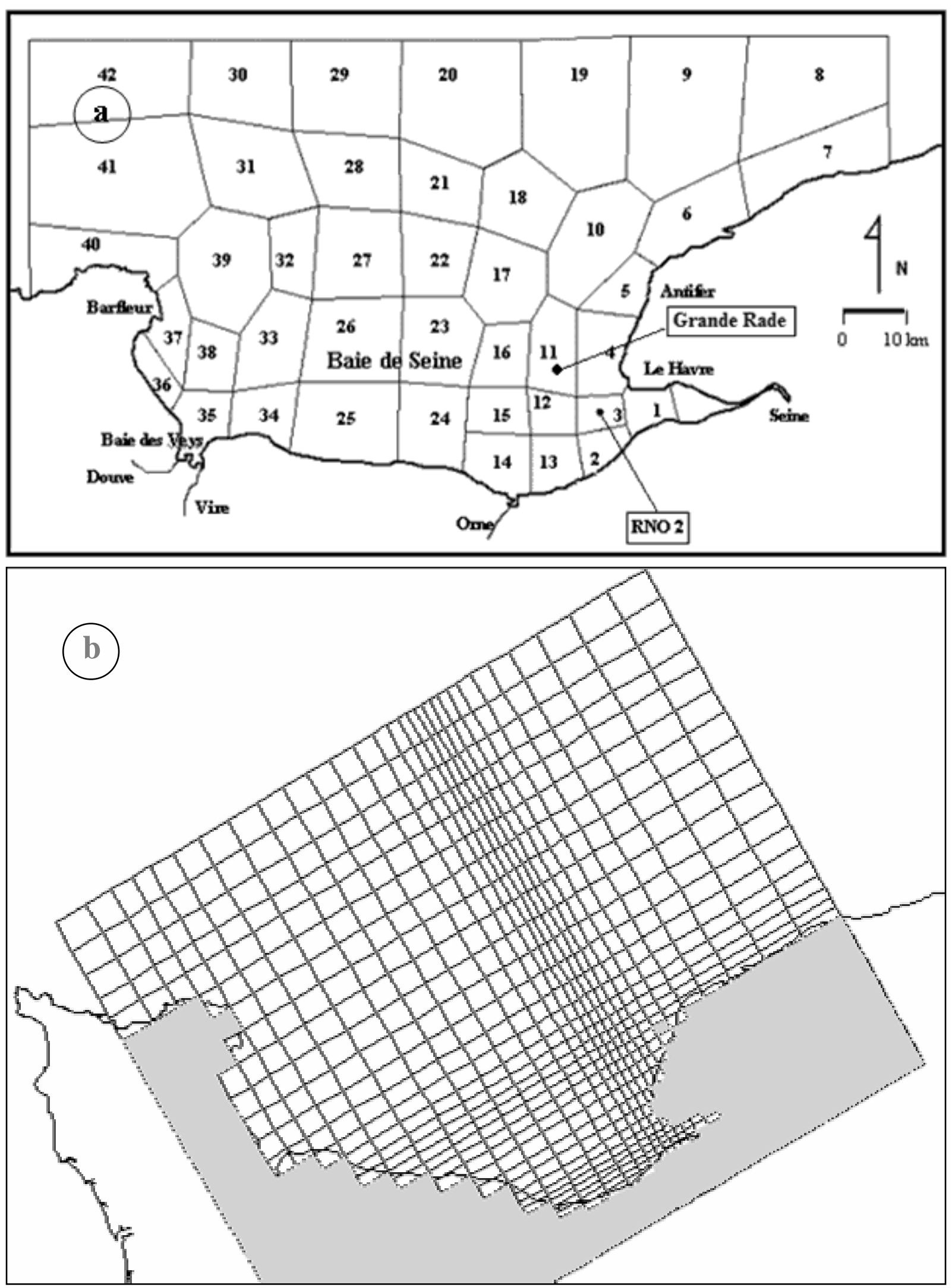

Fig.4 


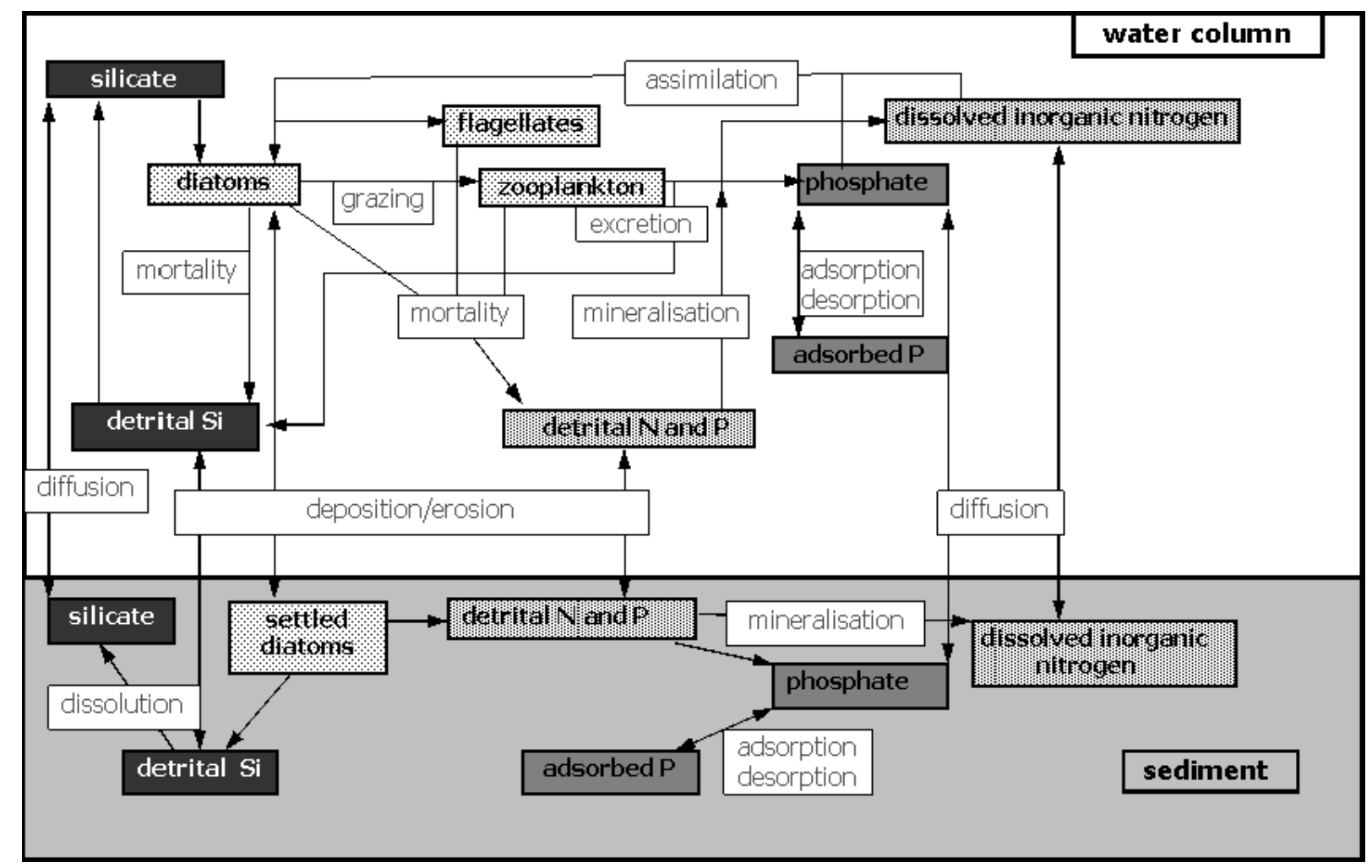

Fig. 5 


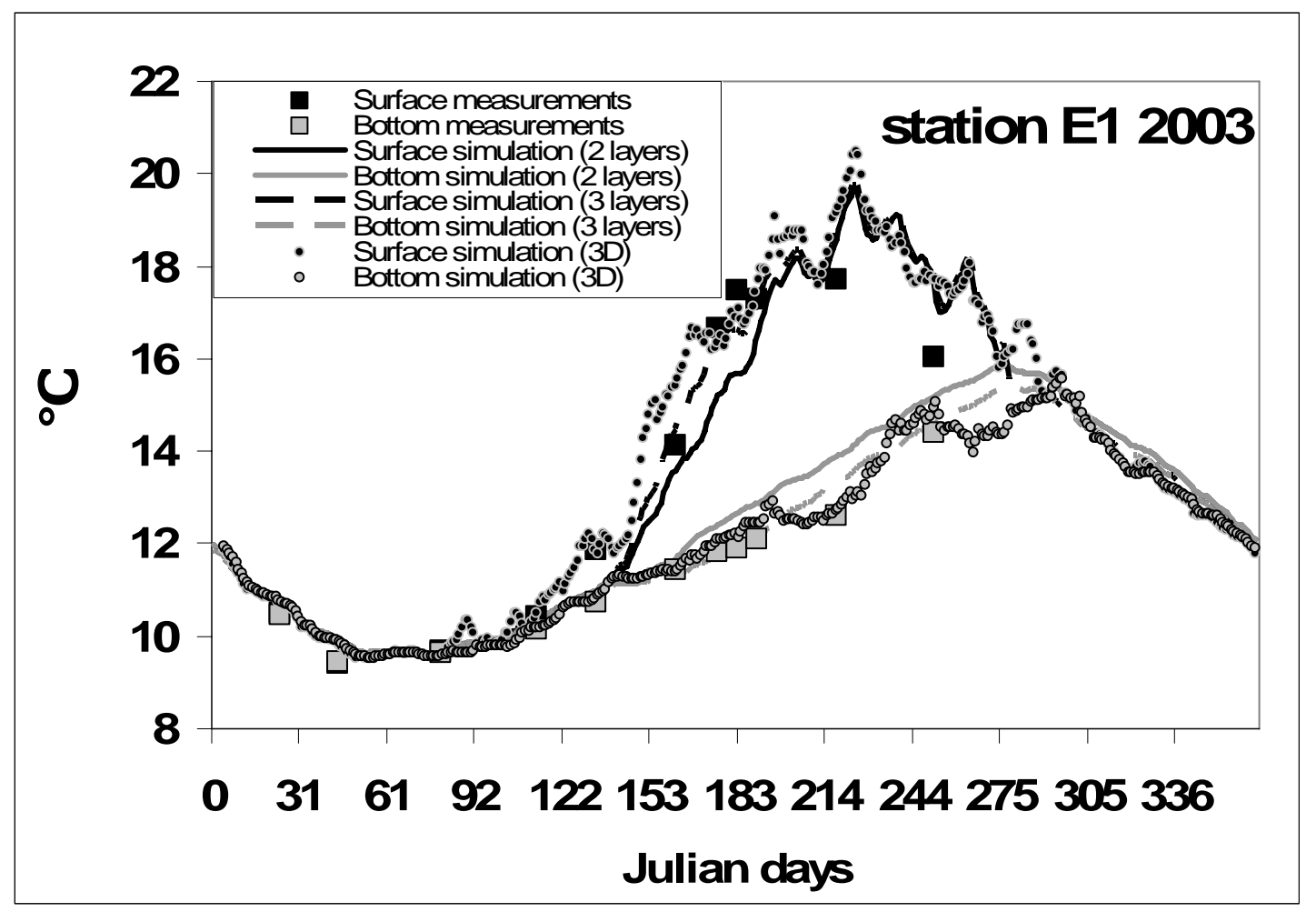

Fig. 6 

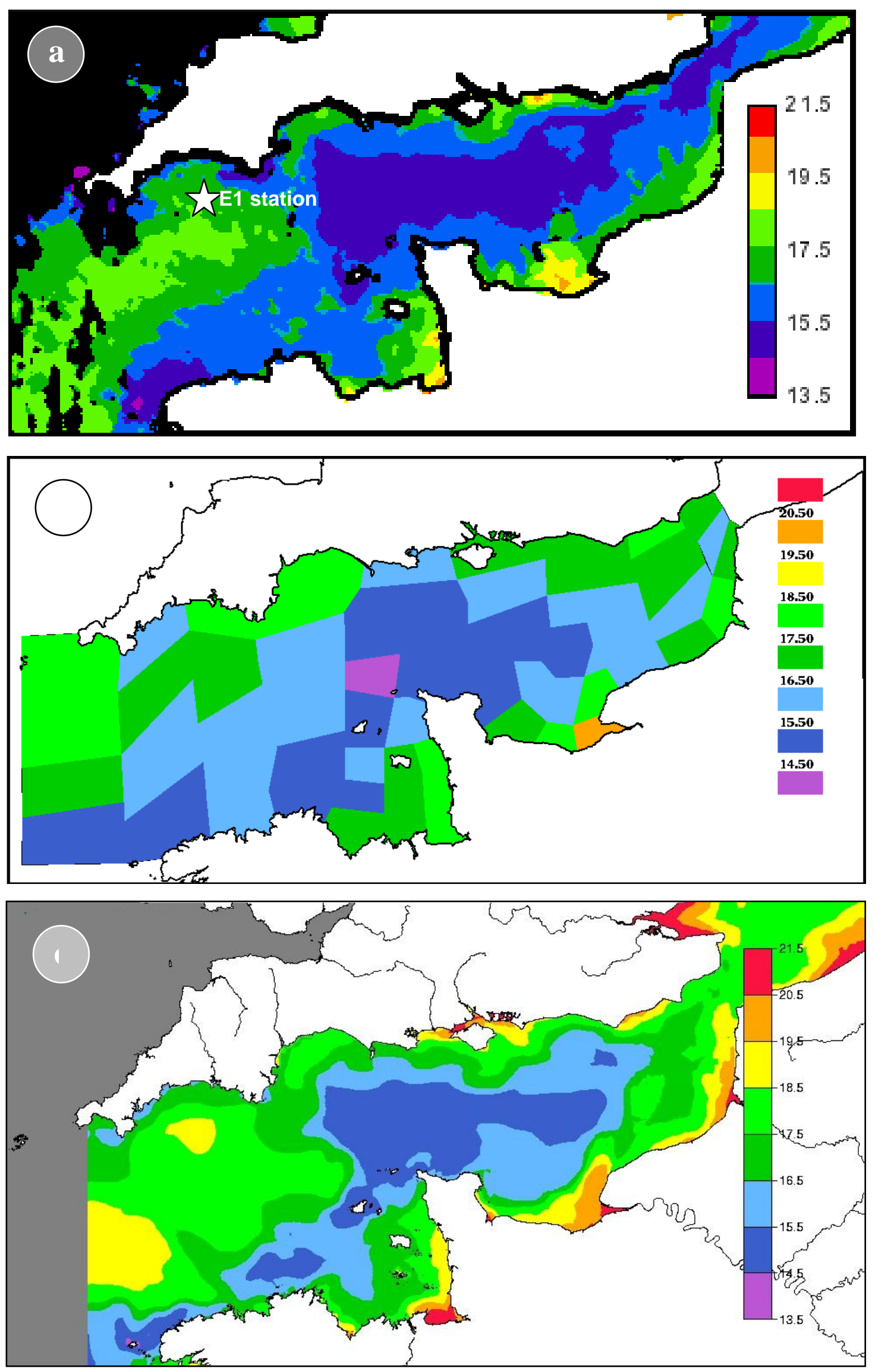

Fig. 7 


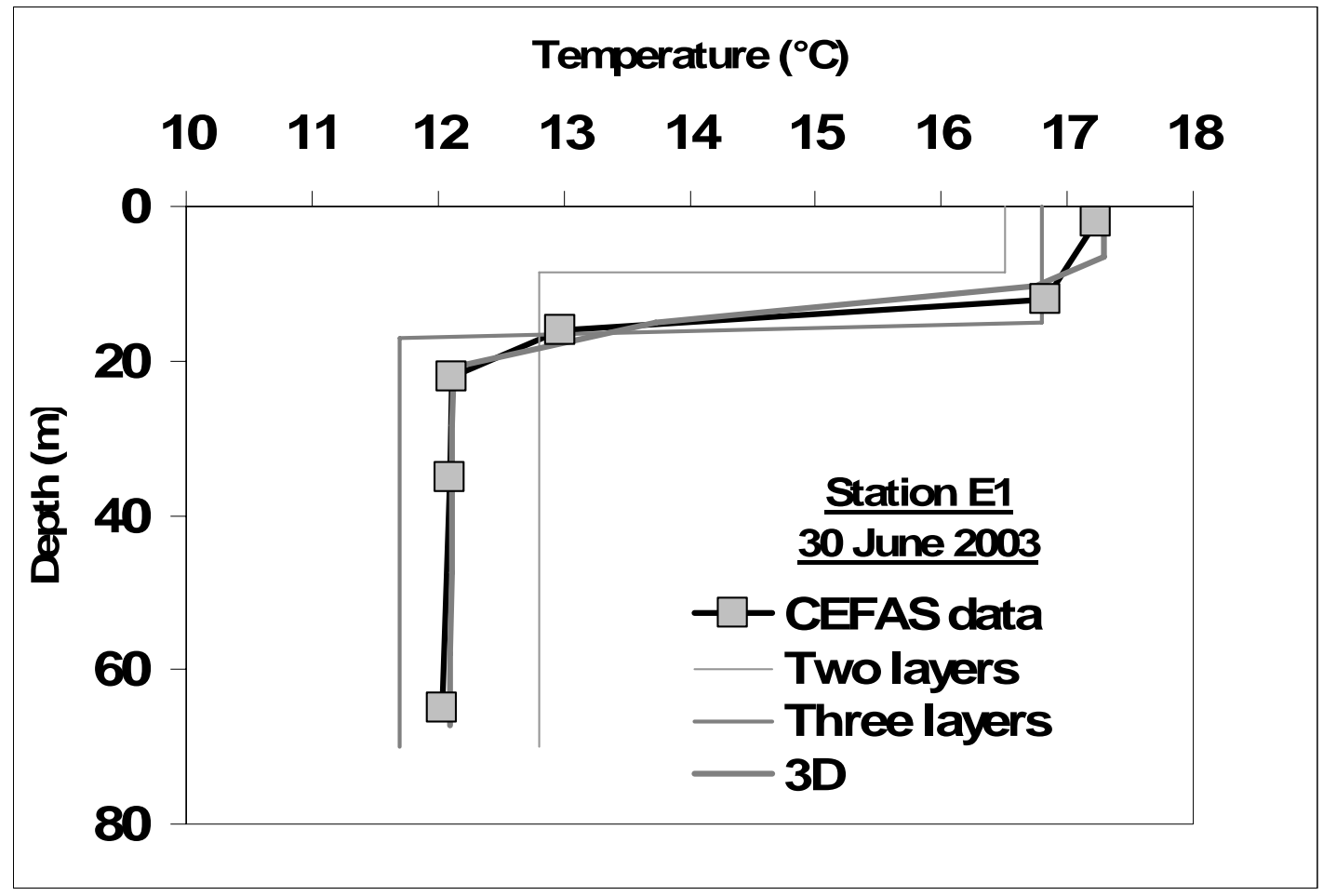

Fig. 8 

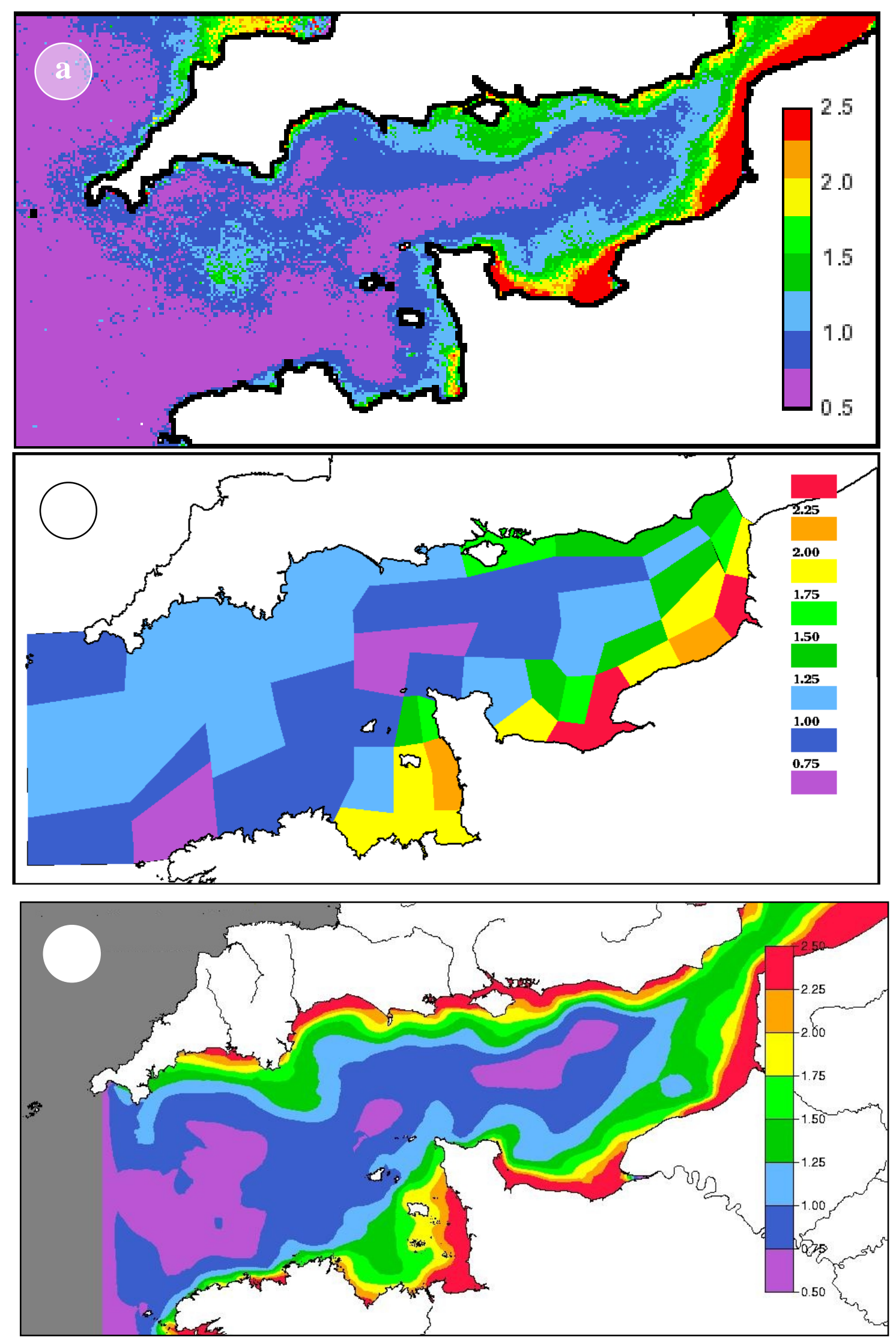

Fig.9 


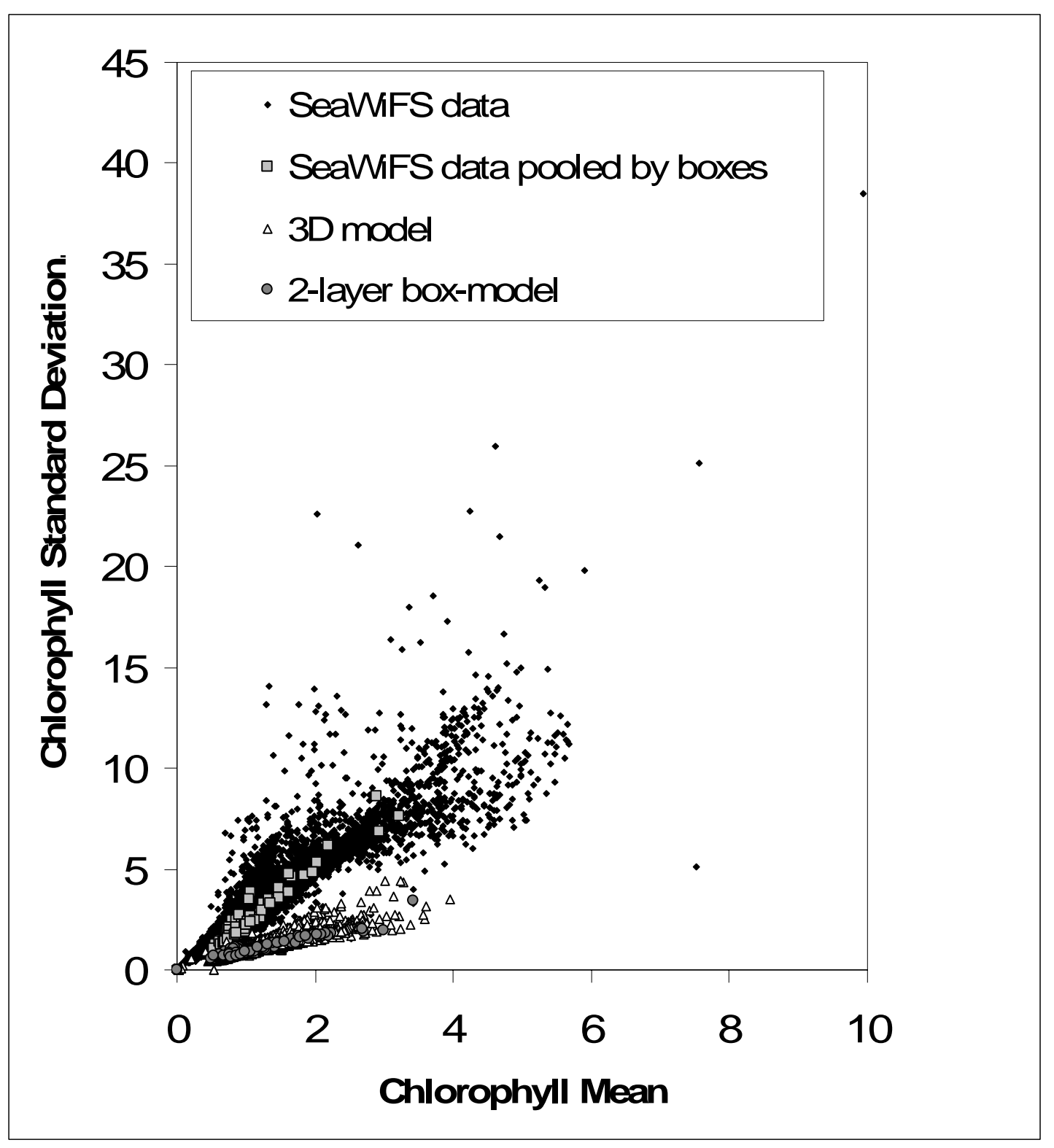

Fig. 10 

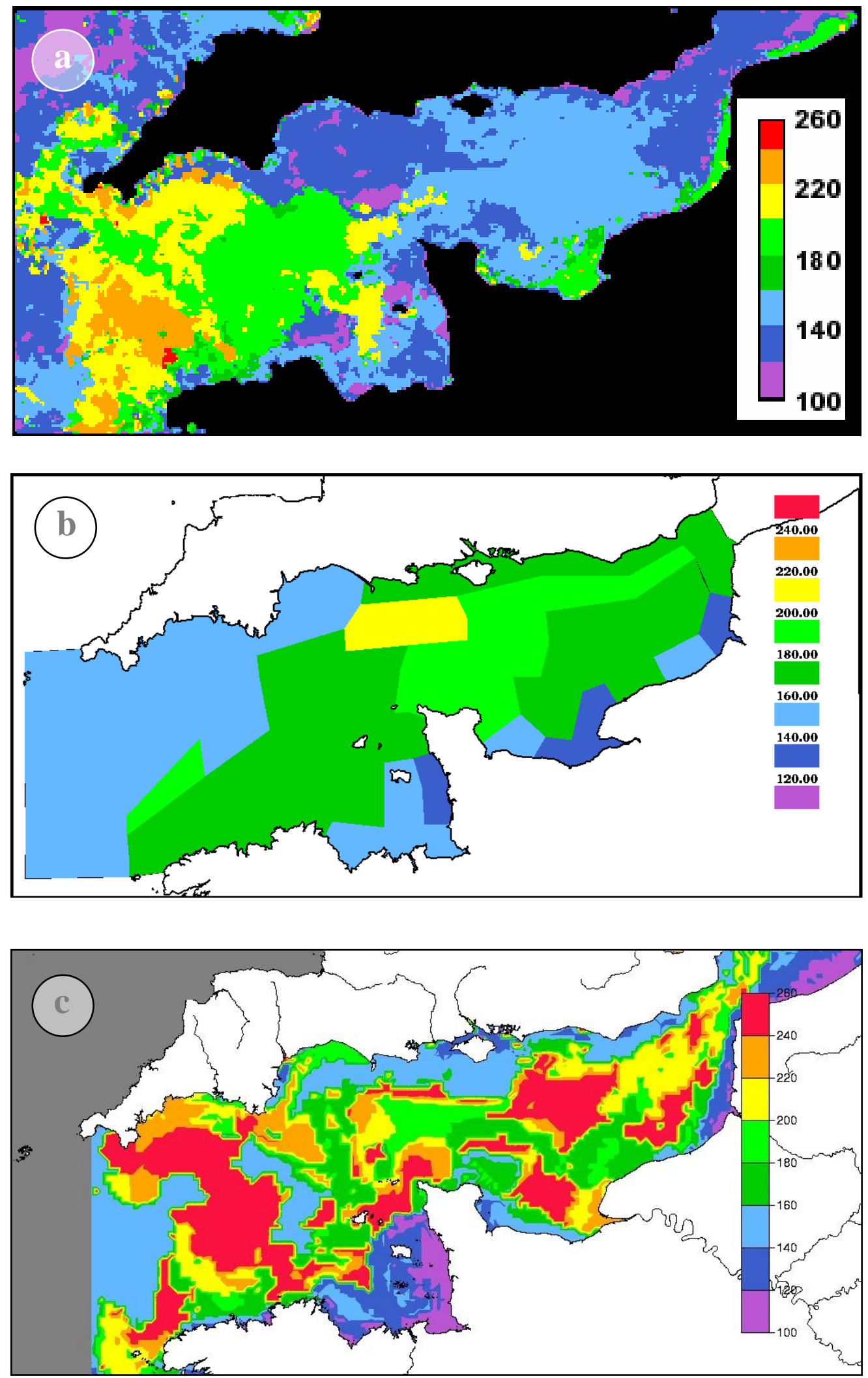

Fig. 11 

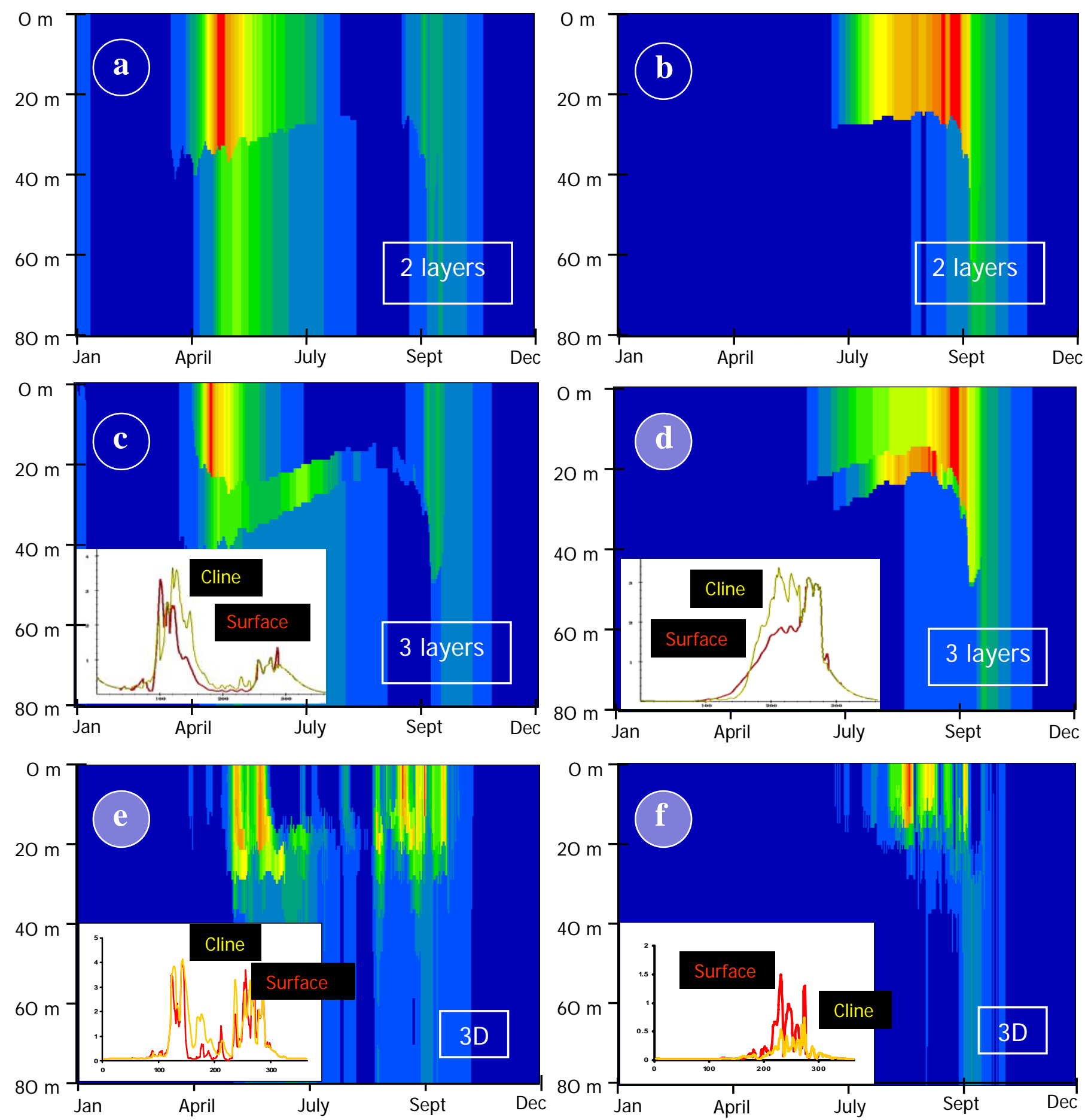

Fig. 12 

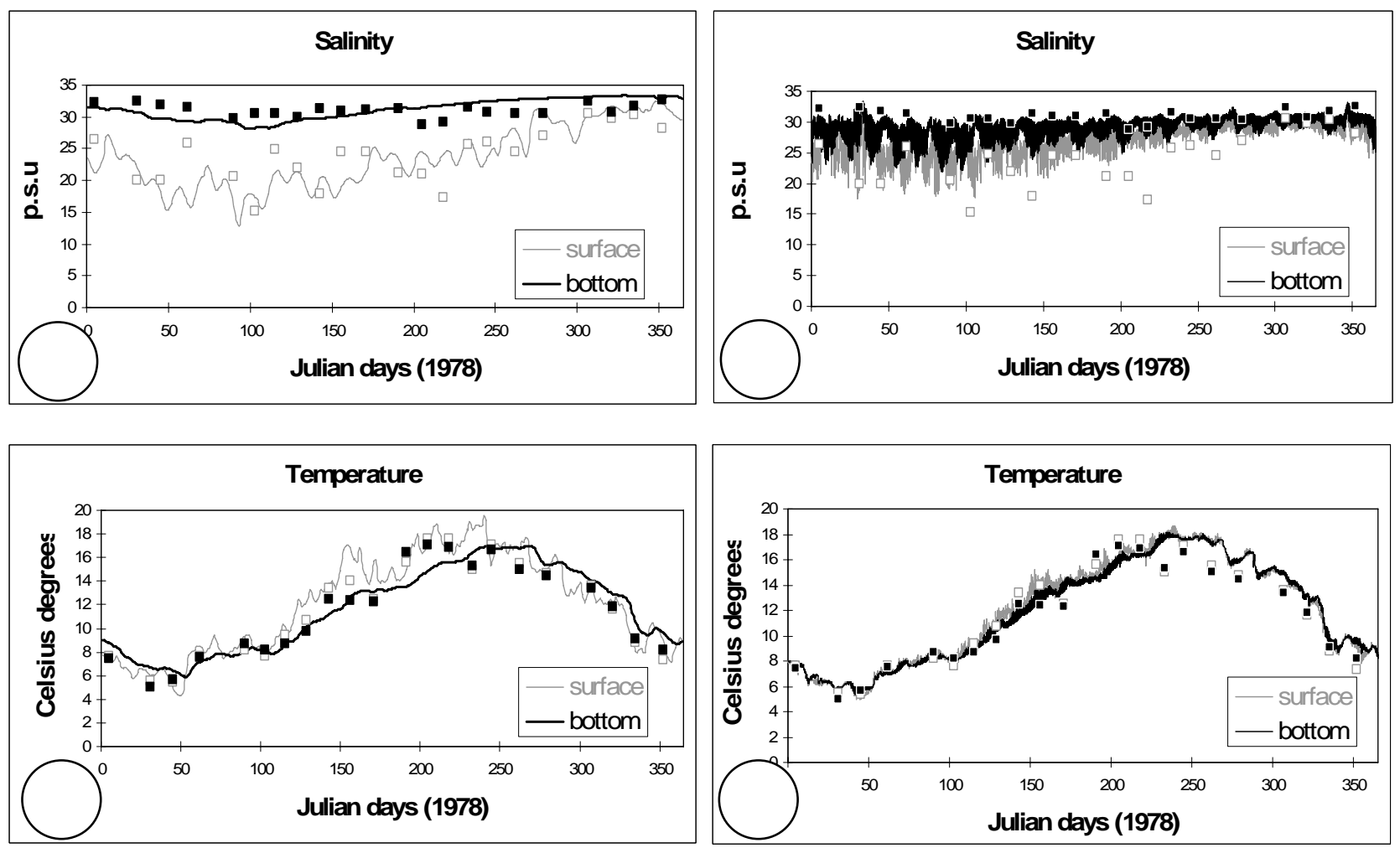

Fig. 13 

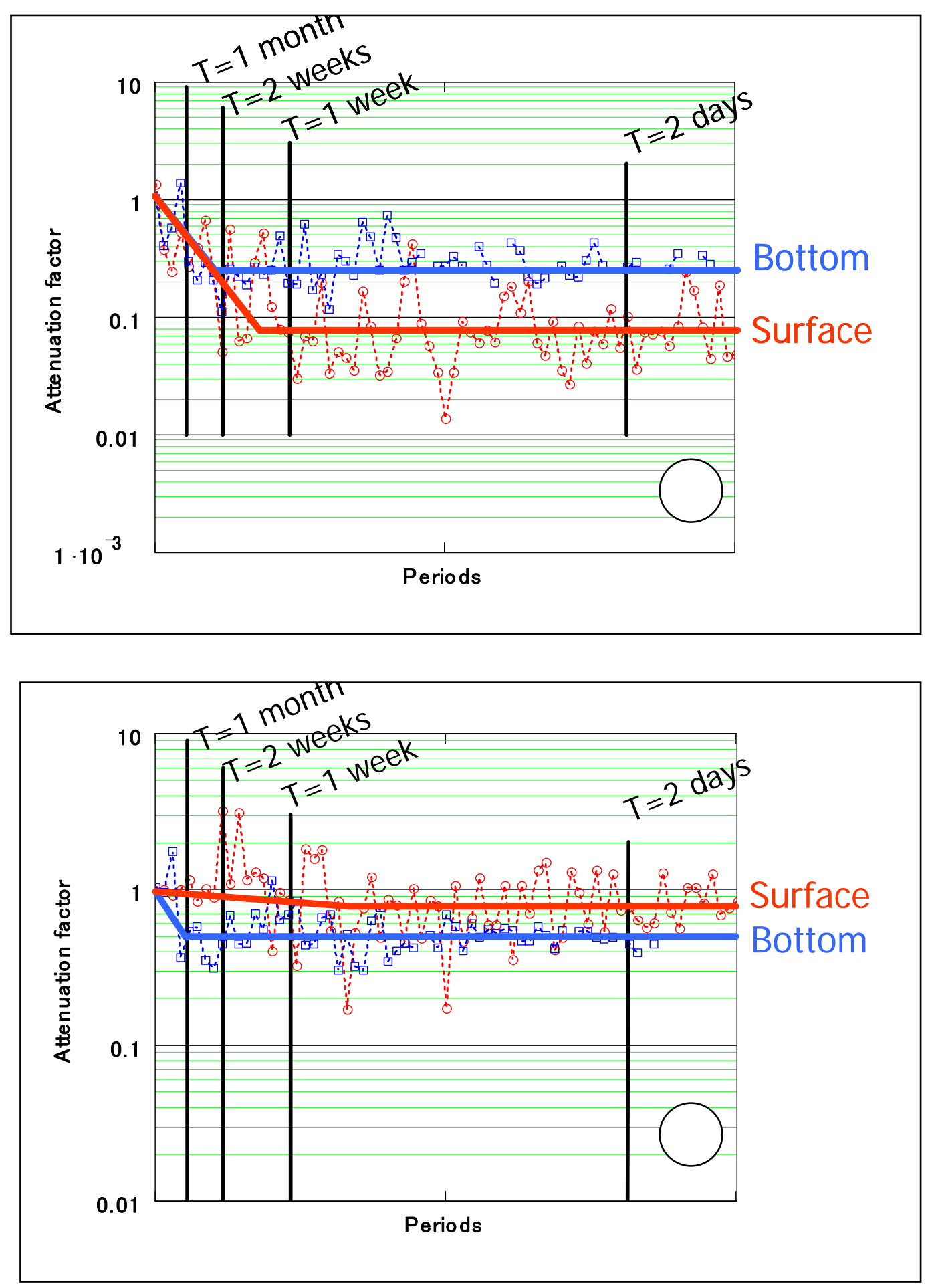

Fig. 14 

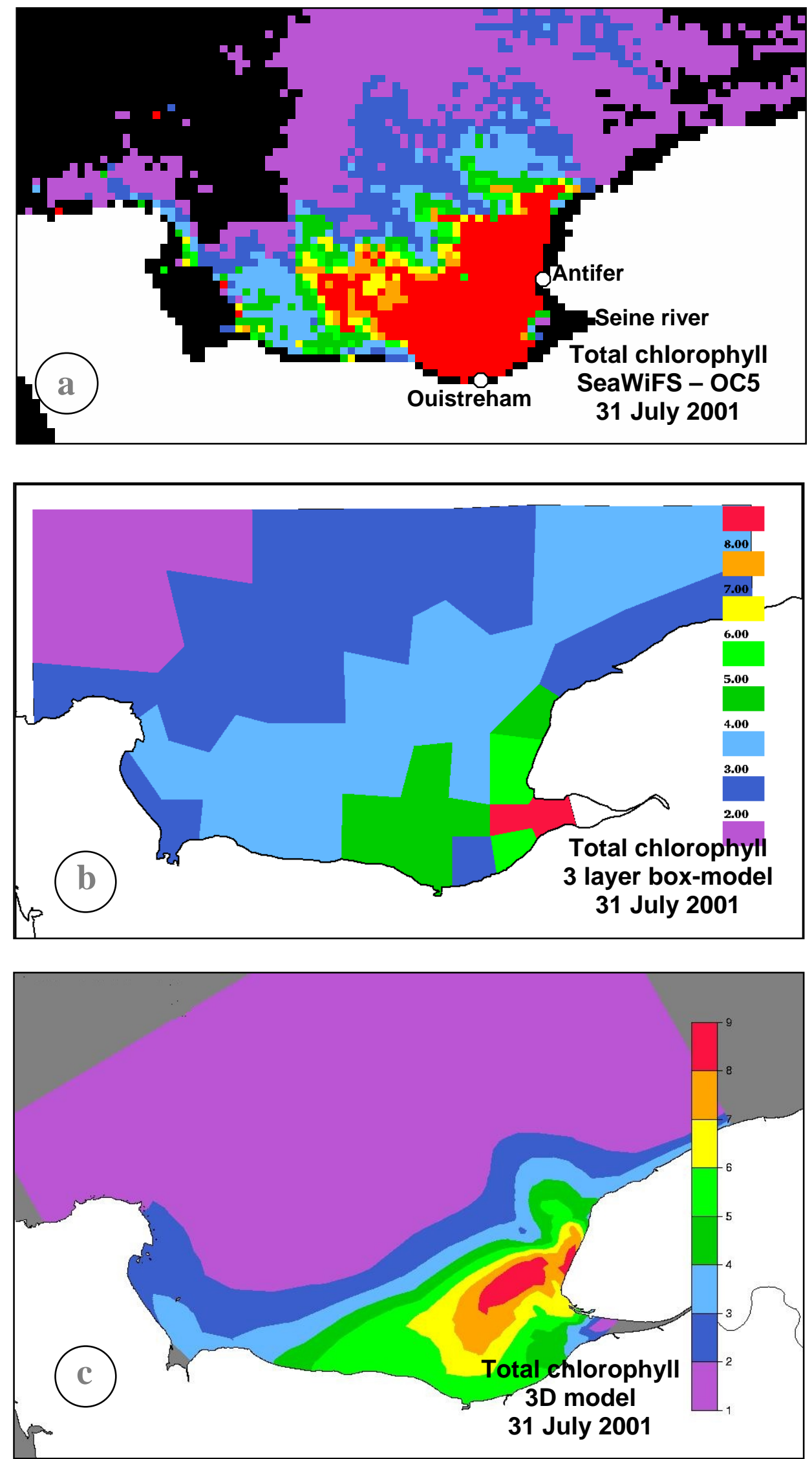

Fig. 15 


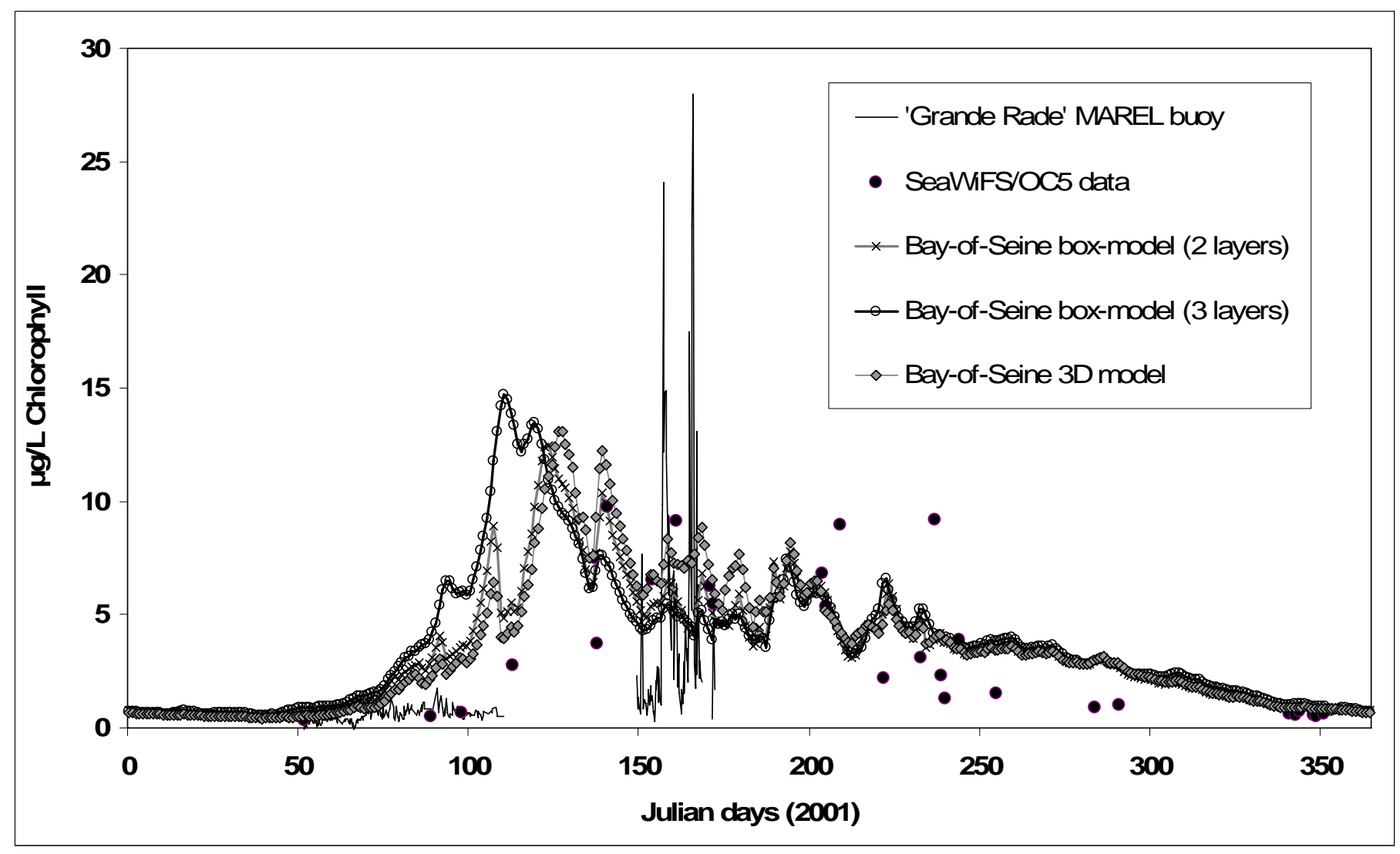

Fig. 16 


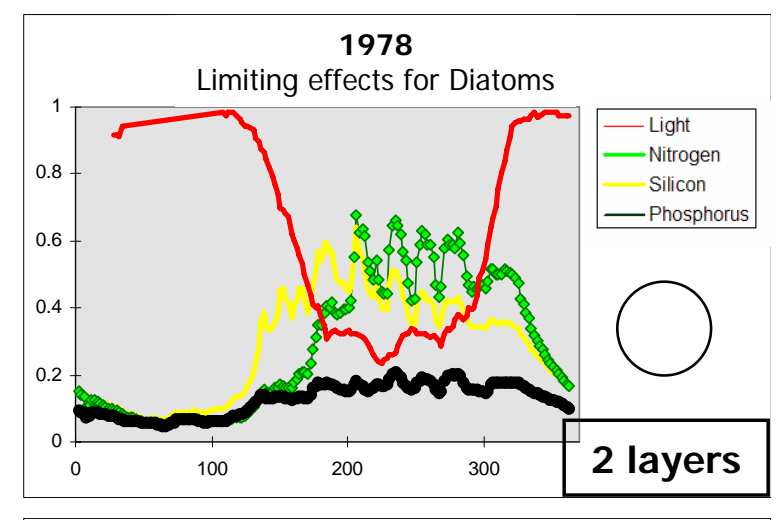

1995

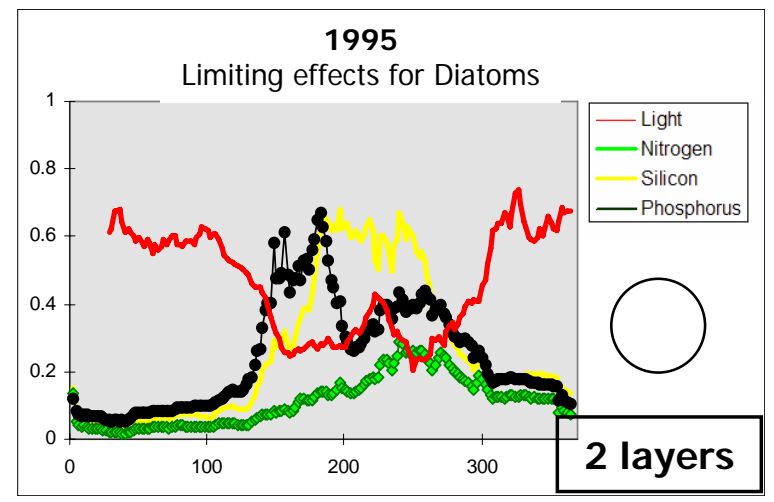

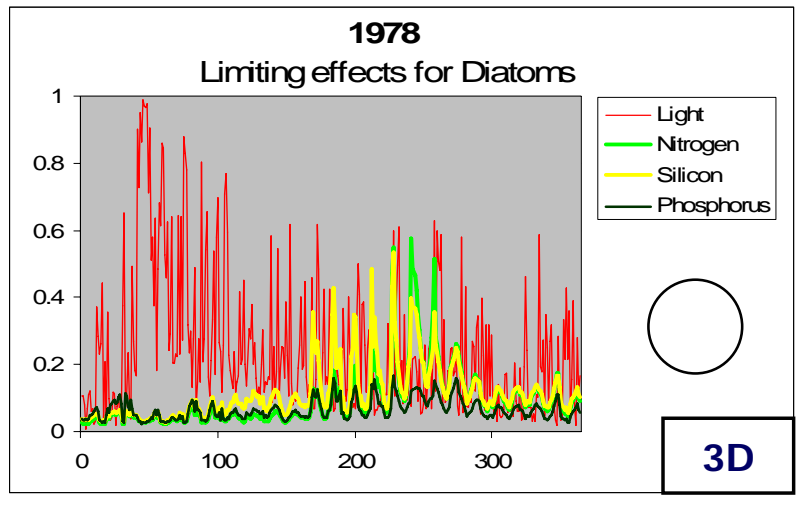

1995

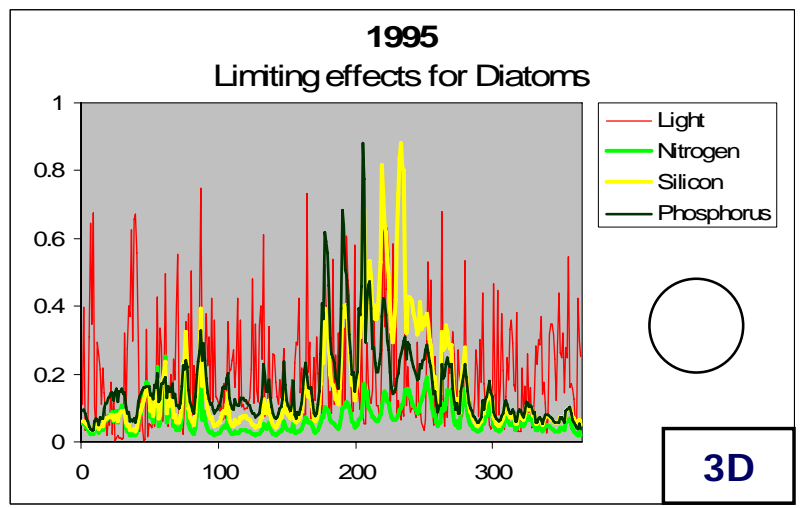

Fig. 17 

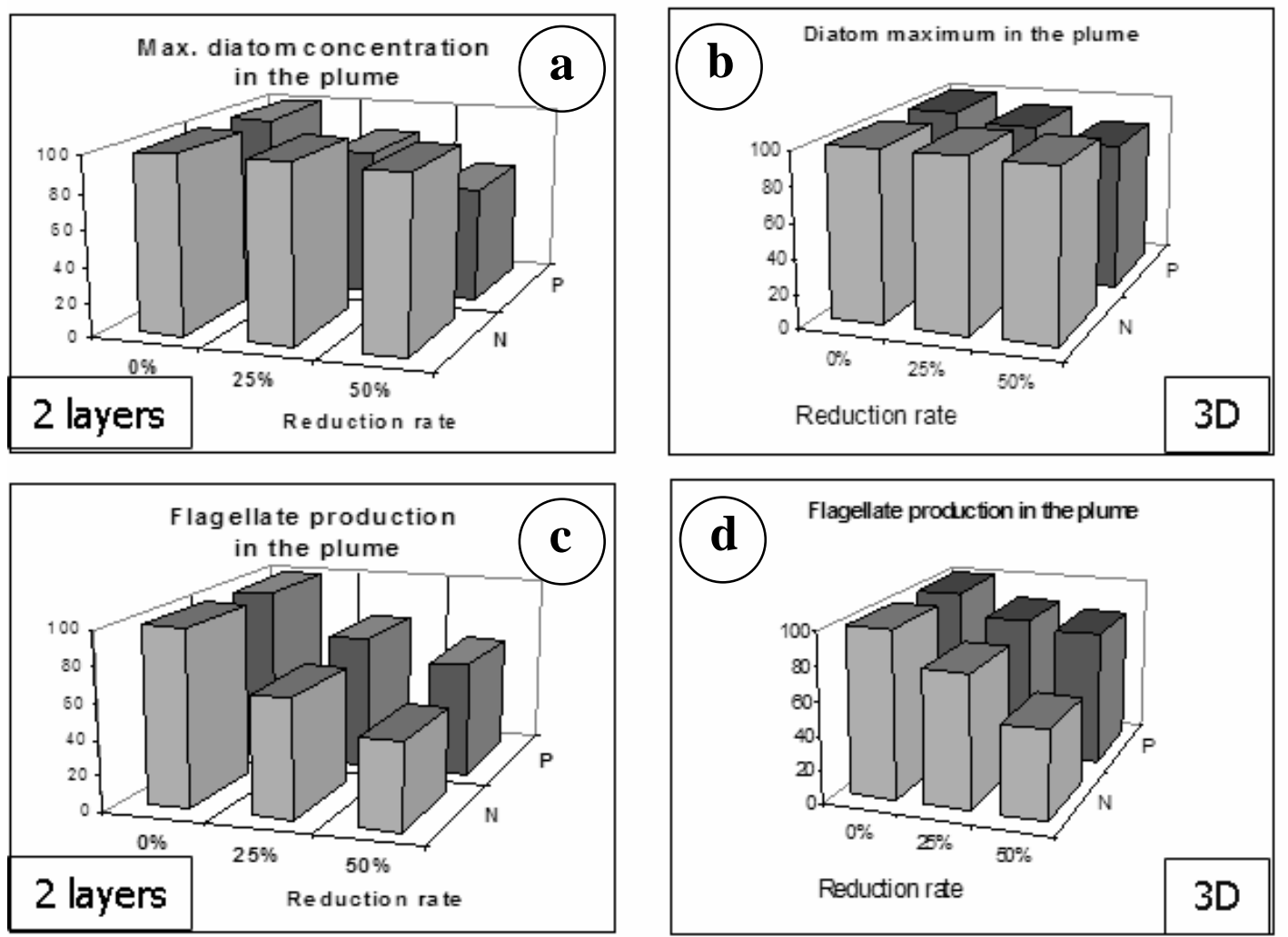

Fig. 18 